\title{
Differential Patterns of c-fos mRNA Expression in Amygdala During Successive Stages of Odor Discrimination Learning
}

\author{
Ursula S. Hess, ${ }^{1}$ Christine M. Gall, ${ }^{1,2,4}$ Richard Granger, ${ }^{3}$ and Gary Lynch ${ }^{2}$ \\ Departments of ${ }^{1}$ Anatomy and Neurobiology, ${ }^{2}$ Psychobiology, and ${ }^{3}$ Computer Sciences \\ University of California \\ Irvine, California 92697
}

\begin{abstract}
Expression of the activity-dependent gene c-fos was used to assess relative levels of neuronal activation in the amygdala and related structures of rats at different stages of odor discrimination learning. In situ hybridization was used to evaluate c-fos mRNA content within the amygdalar subdivisions, the bed nucleus of the stria terminalis, and the hippocampus. After initial exploration of the test apparatus, c-fos mRNA levels were increased in the medial and, to lesser extent, basolateral subdivisions and remained low in the central division. The balance of amygdala to hippocampal labeling favored hippocampus. Rats engaged in familiar nose-poke responses had comparably elevated labeling in the medial and basolateral divisions and low labeling densities in the central division. The ratio of hippocampal to amygdala labeling was at control levels. Rats required to switch from ad libitum responding to cued responding to odors had high basolateral to medial labeling ratios. This was in marked contrast to the medial dominance found in control and exploration rats. Hybridization was substantially more dense in basolateral amygdala than in hippocampal CA1; this imbalance was unique to the group required to form first associations between odors and rewards. Rats performing an overtrained odor discrimination had the least differentiation between amygdalar subdivisions of any behavioral group. The
\end{abstract}

\footnotetext{
${ }^{4}$ Corresponding author.
}

hippocampus-to-amygdala labeling ratio favored hippocampus and was nearly identical to the ratio in exploration rats. These results demonstrate that the balance of activity within and between limbic structures shifts according to behavioral demands. It is suggested that the balances reflect the availability of pertinent afferent cues, interactions between hippocampus and the extended amygdala, and relative levels of activity in the diffuse projections to the limbic system.

\section{Introduction}

Neuroanatomical studies over the past decade have described connections for most cell groups in the amygdala. Much has also been learned about the behavioral and hormonal changes that follow experimental manipulations of the amygdaloid subfields. Together, these lines of evidence support the conclusion that the three subdivisions of the amygdala are engaged in related but distinctly different brain operations. The corticomedial division links the primary and accessory olfactory systems and other amygdaloid subdivisions (Scalia and Winans 1975) with neuroendocrine (Dunn and Whitener 1986; Kato et al. 1986; Schulkin et al. 1989; Rajendren and Moss 1993), sexual (Pfaff and Keiner 1973; Harris and Sachs 1975), and agonistic (Luiten et al. 1985) response systems located in the medial hypothalamus. Extensive bidirectional connections with the brainstem together with extensive experimental evidence indicate that the central division of the amygdala has nociceptive, gustatory, and autonomic functions (Bernard et al. 1996 and references therein). The basolateral division is related to the lateral hypothalamus and por-

LEARNING \& MEMORY 4:262-283 @ 1997 by Cold Spring Harbor Laboratory Press ISSN1072-0502/97 \$5.00

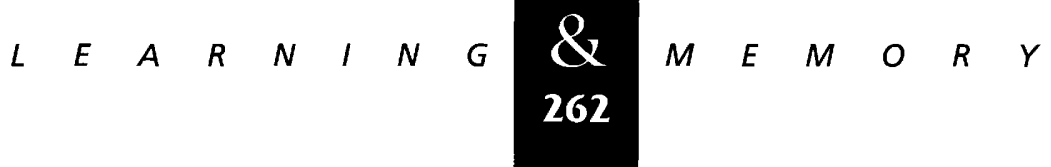


tions of the striatum and is generally thought to contribute to the expression of emotional or appetitive/aversive behaviors (for recent demonstrations, see Maeda et al. 1993; Burns et al. 1994; Liang et al. 1994; Kirouac and Ganguly 1995; Sanders and Shekhar 1995; Hatfield et al. 1996; Maren et al. 1996; for review, see LeDoux 1993a; Davis et al. 1994; Ono et al. 1995).

There is also significant evidence that the divisions of the amygdala have prominent and differential roles in the acquisition and use of memory. Most of the pertinent data concerns the basolateral complex, which is known to be necessary for classical conditioning (Davis et al. 1994; Hatfield et al. 1996), consolidation of inhibitory avoidance (Parent and McGaugh 1994), and acquisition of discriminative conditioning (Muramoto et al. 1993). These and related studies (Gaffan and Harrison 1987; Cador et al. 1989; Everitt et al. 1989, 1991) suggest that the basolateral division is important for the memory of emotionally significant sensory stimuli. A predominant view is that the nuclei within the complex have a role in associating stimuli with their affective response (for review, see Ono et al. 1995). The central division has been proposed as the efferent link for some stimulusresponse associations (LeDoux 1992, 1993a,b; Savander et al. 1995). Finally, there is evidence that the medial division has an important role in types of learning that regulate the expression of agonistic behavior (Luiten et al. 1985; Vochteloo and Koolhaas 1987; Rajendren and Moss 1993).

The above results strongly suggest that relative levels of activity across the subdivisions of the amygdala will vary depending on the type and perhaps stage (acquisition, rehearsal, retrieval) of learning in which the brain is engaged. The primary objective of the present studies was to test this general idea as well as the specific prediction that activation of the basolateral complex will predominate when experienced animals are required to associate neutral cues with positive and negative rewards in the context of performing a familiar behavior. Accordingly, expression of the activity regulated gene c-fos was evaluated by in situ hybridization to c-fos mRNA in groups of rats at different stages of learning to discriminate between simultaneously presented neutral odors. All animals performed in the same apparatus and with the same levels of motivation and differed only with regard to the demands placed on them. These paradigmatic features increased the likelihood that any observed shifts in regional patterns of c-fos expres- sion would be attributable to changes in the processing of environmental cues.

A second question addressed by the present experiments concerned the extent to which the balance of activity in amygdala versus other limbic structures shifts over the different stages of acquiring and using discriminative responses. Neuroanatomical studies have shown that the nuclei in the medial and central amygdala are interconnected densely with discrete cellular groups in the bed nucleus of the stria terminalis. The closeness of these relationships was one factor that prompted the proposal that the amygdala should be viewed as an extended structure (the "extended amygdala") with central and medial components stretching continuously from the ventrolateral to the rostromedial telencephalon (de Olmos et al. 1985; Alheid and Heimer 1988; Alheid et al. 1995). Although the utility of this idea has been disputed (Canteras et al. 1995), it is now clear that hypotheses about the internal operations of the amygdala need to address not only the balance of events between amygdaloid subdivisions but also the balance between those nuclei and their counterparts in the bed nucleus.

Comparisons were also made between activity in the hippocampus versus amygdala. The inputs and targets of these primary components of the limbic system overlap significantly and it is generally assumed that they operate together during performance of complex behaviors. However, it is not known to what degree, or even if, the relative levels of activity in these structures change over the different stages of learning.

Finally, patterns of c-fos expression in the olfactory learning groups were compared with those elicited by manipulations known to have specific effects on neuronal activation within the amygdala (e.g., activation of medial groups with sexual activity and of the central division with stress) (Sharp et al. 1991; Imaki et al. 1993; Sandner et al. 1993; Fernandez-Fewell and Meredith 1994; Beck and Fibiger 1995; Flanagan-Cato and McEwen 1995; Heeb and Yahr 1996; and others; for review, see Bialy and Kaczmarek 1996). These comparisons were intended to provide information pertinent to whether commonalities across the various learning groups reflected a common environment and motivational state as opposed to regional variations in the inducibility of the c-fos gene as assessed by the procedures used in the present studies. Beyond this, the comparison animals allowed for tests of the extent to which the learned behaviors engaged

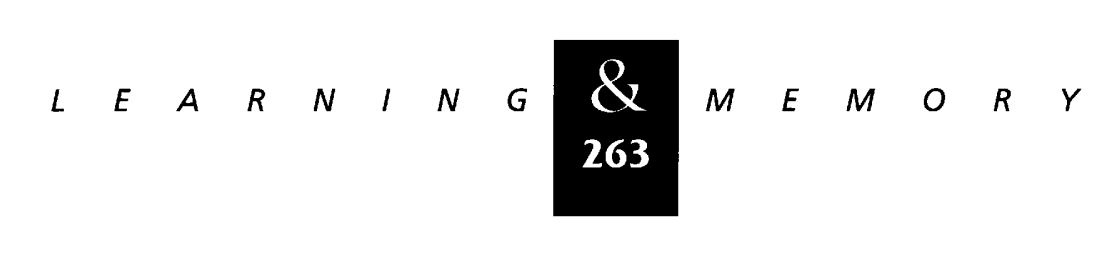


Hess et al.

the same amygdaloid circuitries activated by events with strong emotional associations.

\section{Materials and Methods}

\section{ANIMALS}

Male Wistar rats, 26-38 days old at sacrifice, were used. Rats were obtained from Hilltop Laboratories (Scottsdale, PA) and were housed in groups of four to six in transparent Plexiglas cages $(12 \times 22$ inches) for the duration of the study. Behavioral training and testing sessions were conducted during the light phase of their 12-hr-lightdark cycle. Animals were put on a deprivation schedule that allowed access to water for only 810 min per day. A Harlan-Teklad fat sufficient test diet was given ad libitum. Animals used for behavioral testing were habituated to the experimenters by 2-5 min of daily handling.

\section{TRAINING APPARATUS}

Odor discrimination training was conducted in an open wedge-shaped apparatus consisting of six separate "odor alleys" and an extension at its thin end that served as a starting compartment (for a detailed description, see Hess et al. 1995a). During training, odors were blown into the chamber through small holes found at the end of each alley. Animals made nose-poke responses through larger holes placed directly above the odor outlets. Correct responses were rewarded with $0.025 \mathrm{ml}$ of water administered to the rats through the larger hole. Incorrect responses resulted in a 2-sec strobe flash from a lamp mounted above the test apparatus. Behavioral sessions were conducted in a dimmed room.

Odors were generated by forcing air at a fixed pressure ( 7 liters/min) through pure peppermint extract (Schilling; Hunt Valley, Maryland) or amyl acetate (Fisher; Tustin, California); 1:12 dilution of saturated odor vapor in air was used for each odor to match perceived odor intensities. The odorized air was blown into the training apparatus during trials only.

\section{ANIMAL TREATMENT GROUPS}

Rats performed at different points in a learning sequence resulting in facile performance of a two- odor discrimination: (1) exploration of the novel training apparatus; (2) performance of a familiar nose-poke response for water reward (a preliminary step in odor discrimination training); (3) acquisition of the odor pair in a familiar environment (i.e., switch to cued responding); and (4) performance of the well-learned odor problem (overtrained). A detailed description of the treatment groups is given below. These were the same animal groups evaluated in previous papers focusing on differential activation of hippocampal subfields across behaviors (Hess et al. 1995a,b). In previous publications, the "switch" rats were referred to as "initial learners" because they were acquiring the odor discrimination for the first time.

HOME CAGE CONTROLS (NAIVE)

To evaluate basal levels of c-fos mRNA expression, 10 rats were taken from the home cage, anesthetized, and perfused, as described below. Eight of these animals had not been water-deprived or handled, whereas the remaining two had. Levels of c-fos mRNA in the amygdala and hippocampus of the two previously handled rats did not differ from those in the nonhandled controls. Therefore, the values sampled for the various brain regions were averaged across all 10 rats.

\section{EXPLORATION OF THE NOVEL TRAINING APPARATUS}

Seven rats were water-deprived and handled ( 5 min/day) for 7-10 days. After this period of deprivation and habituation, these rats were placed in the odor training apparatus for $30 \mathrm{~min}$. No odors were presented during this period. All animals explored the chamber actively and were killed immediately thereafter.

NOSE-POKING

Six rats were trained to nose-poke for water reward. Nose-pokes were rewarded at all six holes as long as successive responses were not at the same hole and nose-pokes occurred within $1 \mathrm{~min}$ of the beginning of the trial. Occasionally, rats were reinforced for consecutive nose-pokes at the same location to prevent them from becoming unresponsive.

Rats were trained to nose-poke for $30 \mathrm{~min} /$ day for 4 days. On the fifth day, they performed the

$$
\text { n..... 圆 }
$$


familiar nose-poke task until they became satiated and stopped responding $(57 \pm 8 \mathrm{~min} ; 152 \pm 33$ trials). Immediately following this session, rats were killed. Animals were killed over the course of 3-4 days. To prevent deterioration of the nose-poke response over this period, rats not being killed on a particular day performed additional 15-min nosepoking sessions each day before the final test session.

SWITCH TO CUED RESPONDING/ACQUISITION OF TWO-ODOR DISCRIMINATION

Following nose-poke training, six animals acquired an odor discrimination problem in the now familiar training apparatus. Rats learned to nosepoke at the positive odor (peppermint) port for a water reward and to avoid the negative odor (amyl acetate) port, which resulted in a brief strobe flash. For each trial, the odors were randomly assigned to two of the six arms. Nose-pokes into unassigned holes had no consequence, as long as a correct or incorrect response was made within $1 \mathrm{~min}$. After this time had elapsed, the rat was returned to the start chamber to begin the next trial.

Animals performed $117 \pm 36$ trials before reaching learning criteria-80\% correct in the last block of 10 trials and active avoidance of the negative odor. Rats were required to maintain this level of performance for $30 \mathrm{~min}$ following "learning," immediately after which they were killed. The 30min time point was chosen because c-fos mRNA levels have been shown to peak at about this time following various forms of stimulation (Shin et al. 1990; for review, see Morgan and Curran 1991). In total, those rats switched to cued responding completed $168 \pm 33$ trials in $112 \pm 19 \mathrm{~min}$. Nose-poke animals were matched as closely as possible for the number of trials switch rats performed.

PERFORMANCE OF A WELL-LEARNED TWO-ODOR DISCRIMINATION (OVERTRAINED)

Five rats were "overtrained" on the odor discrimination problem described above. These animals first underwent nose-poke training (50 $\mathrm{min}$ total in 2 days). Then, over the course of several sessions, they were trained on the discrimination [peppermint $(+)$, amyl acetate $(-)$ ]. Rats took an average $( \pm$ s.D.) of $171 \pm 54$ trials to reach learning criteria. Following acquisition of the problem, training was continued for 4-5 days ( $274 \pm 38$ trials), during which time rats maintained their level of performance. The variability in training sessions resulted from different rates of learning by the animals. On the last day, animals again performed on the familiar problem ( $66 \pm 5$ trials in $30 \mathrm{~min}$ ), after which time they were killed. Virtually no errors were made in this session.

\section{COMPARISON GROUPS}

COPULATION

Two male Long Evans rats (560-595 grams; from Zivic-Miller) received extensive sexual experience with receptive females over the course of -4 months during which time they had sexual encounters an average of three times per week. On the test date, they were once again each placed with a receptive female rat, their behavior was monitored, they were removed from the testing environment and killed 30 min following the start of the encounter. Both male rats mounted and intromitted several times and ejaculated twice during the session. Female rats had been rendered receptive and proceptive via subcutaneous injections of $150 \mu \mathrm{g}$ of estradiol benzoate $48 \mathrm{hr}$ before and 750 $\mu \mathrm{g}$ of progesterone $4 \mathrm{hr}$ before testing. As these rats had been part of another study, they had received regular intraperitoneal (IP) injections of either cyclodextrin vehicle (2-hydroxypropyl- $\beta$-cyclodextrin, $33 \% \mathrm{w} /$ vol with $0.45 \% \mathrm{NaCl}$ ) or an experimental drug [the AMPA receptor up-modulator 1-(quinoxalin-6-yl-carbonyl)piperidine; $35 \mathrm{mg} / \mathrm{kg}$ ], and on the final testing day were again injected IP with cyclodextrin $5 \mathrm{~min}$ before the session.

\section{STRESS/INJECTION}

Eleven male Sprague-Dawley rats (240-280 grams) received consecutive IP injections of cyclodextrin (2-hydroxypropyl- $\beta$-cyclodextrin, 33\% w/ vol with $0.45 \% \mathrm{NaCl}$ and $0.9 \% \mathrm{NaCl}$ (both at 1 $\mathrm{ml} / \mathrm{kg}$ ). These animals had been handled previously ( $5 \mathrm{~min} / \mathrm{day}$ ) and placed in the test chamber for 4 days before the experimental session. After receiving the test injections, the rats were left in the apparatus $(55 \mathrm{~cm}$ wide $\times 31 \mathrm{~cm}$ deep $\times 61 \mathrm{~cm}$ high, with clear Plexiglas sides) for $30 \mathrm{~min}$, after which time they were killed with an overdose of sodium pentobarbital.

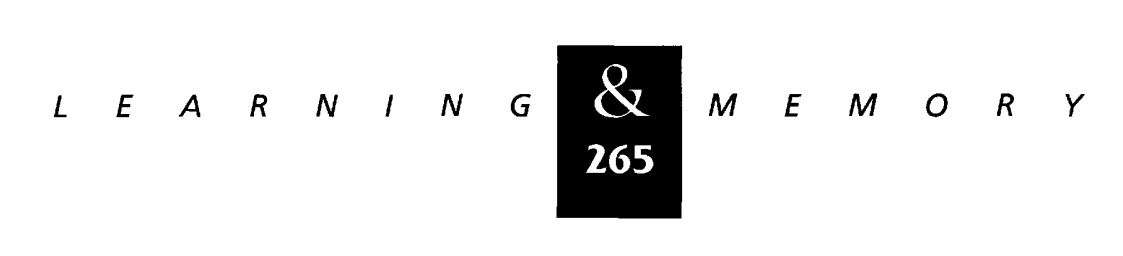


Hess et al.

c-fos cRNA PROBE

A ${ }^{35}$ S-labeled cRNA probe complementary to rat c-fos mRNA [i.e., to positions 583-1250 of clone pc-fos (rat)-1 by Curran et al. (1987)] was used. The antisense cRNA was transcribed from Pst I-linearized recombinant clone $\mathrm{pBS} / \mathrm{rfos}$ with T7 RNA polymerase in the presence of uridine 5'$\left[\alpha^{-35}\right.$ S] thiotriphosphate. The sense RNA sequence was generated from the same template with T3 RNA polymerase after linearization with EcoRI.

\section{IN SITU HYBRIDIZATION}

Animals were killed with an overdose of sodium pentobarbital and intracardially perfused with $4 \%$ buffered paraformaldehyde. Brains were postfixed and cryoprotected, and coronal tissue sections ( $30 \mu \mathrm{m}$ thick) were cut on a freezing $\mathrm{mi}$ crotome. The tissue was processed for c-fos cRNA hybridization as described previously (Gall et al. 1991, 1995; Lauterborn et al. 1993). Hybridization to both sense and antisense probes was conducted at $60^{\circ} \mathrm{C}$ for $37-43 \mathrm{hr}$ with the ${ }^{35} \mathrm{~S}$-cRNA at a concentration of $1 \times 10^{6} \mathrm{cpm} / 100 \mu \mathrm{l}$. Following this, sections were treated with $20 \mu \mathrm{g} / \mathrm{ml}$ of RNase A (35-45 $\mathrm{min}, 45^{\circ} \mathrm{C}$ ) and washed through descending concentrations of SSC (saline sodium citrate buffer). The distribution of hybridization was evaluated using Amersham $\beta$-max Hyperfilm and Kodak NTB2 emulsion autoradiography with exposure intervals of 1-2 days and 2-3 weeks, respectively. No cellular labeling was seen in tissue hybridized to the sense probe or treated with RNase A before hybridization.

\section{AUTORADIOGRAPHIC ANALYSIS}

An Intel-based MCID image analysis system (Imaging Research, St. Catherine's, Ontario, Canada) was used for densitometric analysis of film autoradiographs. Film optical densities were calibrated relative to densities obtained from ${ }^{14} \mathrm{C}$-labeled brain paste standards. This allowed for the conversion of optical density readings to $\mathrm{cpm} / 25$ $\mu \mathrm{g}$ protein (see Gall et al. 1994). Levels of c-fos cRNA hybridization were quantified in three subdivisions of the amygdala (as defined by Paxinos and Watson 1986): (1) the basolateral division [predominantly basolateral amygdaloid nucleus, anterior part (BLA), but also including basolateral amygdaloid nucleus, posterior part (BLP) and basolateral amygdaloid nucleus, vental part (BLV) when activated, as the labeling was used as a guide in sampling]; (2) the central division [central amygdaloid nucleus, medial division (CeM) and central amygdaloid nucleus, lateral division (CeL)]; and (3) the medial division [medial amygdaloid nucleus (Me), medial amygdaloid nucleus, anterodorsal part (MeAD), medial amygdaloid nucleus, anteroventral part (MeAV), medial amygdaloid nucleus, posterodorsal part (MePD), and medial amygdaloid nucleus, posterovental part (MePV)]. Most of these regions are shown in schematic form in Figure 1. For each region, measures were collected from at least 3-5 tissue sections cut at different rostrocaudal levels. Occasionally, only 2 sections were sampled. For each section, both sides of the brain were measured. Individual measures were averaged to yield a mean and standard deviation for each animal.

The different animal treatment groups were tested in a series of studies investigating patterns of
Figure 1: Schematic illustrations of the cytoarchitectonic organization of the rostral $(A)$ and caudal $(B)$ amygdala at approximately the same levels illustrated in subsequent photographic plates. These schematics were taken from Swanson (1992); the nomenclature for the nuclear groups has been slightly modified to conform with the atlas of Paxinos and Watson (1986). (ACo) Anterior cortical amygdaloid nucleus; (BMP) basomedial amygdaloid nucleus, posterior part; (c) central nucleus amygdala, capsular part; (CEI) central amygdaloid nucleus, lateral division; (CP) caudate/putamen (striatum); (m) central nucleus amygdala, medial part; (LA) lateral amygdaloid nucleus; (Iv) lateral ventricle; (Pir) piriform cortex; (PLCo) posterolateral cortical amygdaloid nucleus; (PMCo) posteromedial cortical amygdaloid nucleus. Other abbreviations are defined in the text.
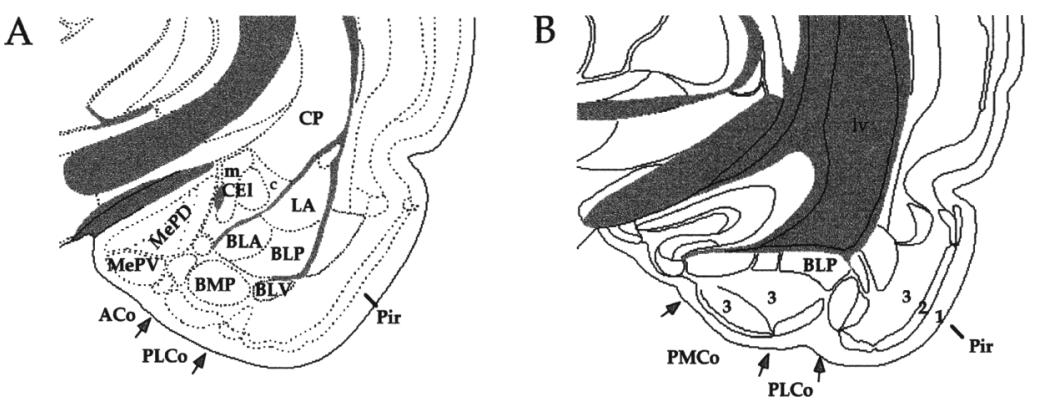
brain activation across sequential stages of odor learning. Animals in each of the five conditions were not always processed concurrently for in situ hybridization. Therefore, to account for slight variability across hybridization "runs," average tissue background values sampled in the molecular layer of the dentate gyrus were subtracted from all mean measurements from each rat. Ratios of c-fos cRNA hybridization density were also calculated to determine the relative balance of gene expression between areas within the same animal. This served as a means of internal normalization in and of itself, and was done on raw numbers before tissue background values were subtracted. The ratios were calculated on each subject first and then averaged for the group. One-way analysis of variance (ANOVA) was used for statistical evaluation. The Student-Newmann-Keuls (SNK) test was used for post-hoc comparisons. Unless otherwise stated, $P$ values are for the SNK test and for comparison with values in the home cage control group. Pearson parametric correlation coefficients were determined using data that had not been normalized by subtraction of tissue background. Differences were considered to be significant when a $95 \%$ confidence level was reached $(P \leqslant 0.05)$.

In previous work (Hess et al. 1995a,b), c-fos cRNA hybridization densities were measured in three subfields of the dorsal hippocampus for the same groups described above. Specifically, CA1b and CA3 stratum pyramidale, and the dorsal blade of stratum granulosum were sampled. These values are used in the present study for purposes of comparison to levels of expression found in the amygdala.

\section{COMPUTER-GENERATED FIGURES}

Images of film autoradiographs were digitized and captured using a CCD video camera module, a Power Macintosh 8500 computer, and the public domain program NIH Image, developed by Wayne
Rasband at the U.S. National Institutes of Health. A gray-scale "look-up table" was chosen that best demonstrated the experimental effects. This lookup table was applied to all computer generated figures, except Figure 2, which shows a representative naive animal. For this rat, a grayscale look-up table was chosen that enhanced regional differences in labeling even further. Despite this manipulation, labeling in this rat still appears lower than that for the other animals. In any case, these figures were intended for qualitative comparisons and quantitative data are also given.

\section{Results}

\section{CONTROLS}

As shown in Figure 2, labeling densities were generally low in the amygdala of home cage controls. Some related structures, such as the bed nucleus of the accessory olfactory tract and the nucleus of the lateral olfactory tract (data not shown), contained modest levels of c-fos mRNA and therefore stood out in this regard. Labeling within the amygdala was not uniform however. The anterior cortical, anterior medial, medial, and posteroventral medial nuclei appeared to be labeled more densely than neighboring structures (Fig. 2A). Densitometric measurements confirmed that differences were present between the amygdaloid subdivisions in control rats $(P<0.0001$, repeated measures ANOVA) with the medial division being labeled most densely $(P<0.001$ vs. central; $P<0.01$ vs. basolateral; SNK). Labeling densities in the basolateral nuclei were also slightly greater than those in the central nuclei $(P<0.05$; SNK).

\section{EXPLORATION}

Figure 3 shows film autoradiographs of coronal sections through the amygdala for a typical rat

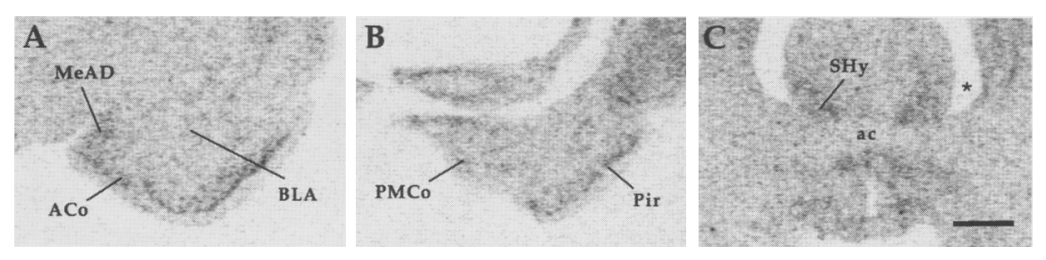

Figure 2: Photographs of film autoradiographs showing levels of c-fos $\left[{ }^{35} \mathrm{~S}\right] \mathrm{CRNA}$ labeling in rostral amygdala $(A)$, caudal amygdala $(B)$, and septum $(C)$ of a representative home cage control rat. Hybridization densities are generally low but not uniform. Relatively greater labeling is evident in the piriform cortex ( $\mathrm{Pir} ; A, B)$ and the MeAD $(A)$. In the septum $(C$ ), the septohypothalamic nucleus (SHy) is somewhat more densely labeled than surrounding structures. (ac) anterior commissare. Bar, $1 \mathrm{~mm}$.

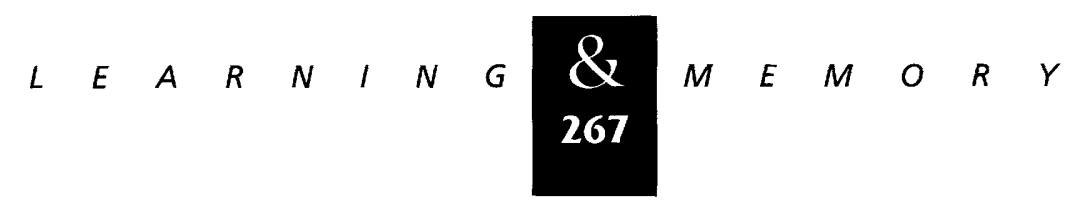


Figure 3: Film autoradiographs showing patterns of c-fos mRNA expression in the amygdala and septum of exploration rats. A rostrocaudal series of coronal sections through the amygdala $(A-E)$ illustrates particularly dense hybridization in the medial division, including the anterodorsal (MeAD), medial (Me), and posteroventral (MePV) nuclei but not the posterodorsal nucleus (MePD). Labeling is also dense in the posteromedial cortical nucleus (PMCo; $E$ ). The BLA and lateral (LA) nuclei have prominent labeling $(B)$, whereas the lateral central nucleus (CeL) stands out as having very low den-
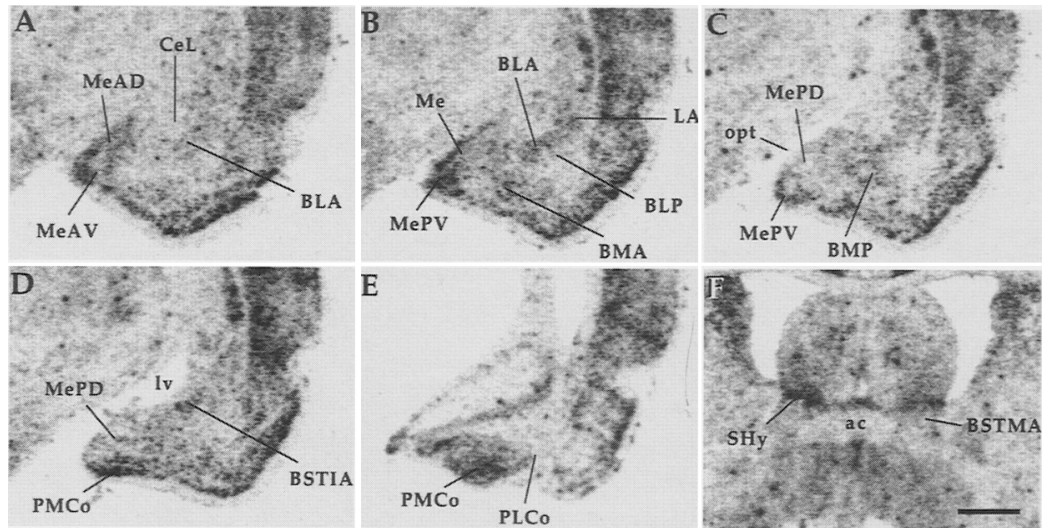

sity labeling $(A)$. (B) (BMA) Basomedial amygdaloid nucleus, anterior part. $(C)$ (opt) Optic tract. As shown in $F$, the septohypothalamic nucleus (SHy) is more densely labeled than surrounding structures. (BSTMA) Bed nucleus of the stria terminalis, medial division, anterior part. See text for other abbreviations. Bar, $1 \mathrm{~mm}$.

from the exploration group. In this group, the highest c-fos mRNA levels were located in the medial division (Fig. 3A,B). Dense hybridization was evident in this division from the most rostral aspects of the amygdala and included the anterodorsal, medial, and posteroventral nuclei but not the posterodorsal nucleus (Fig. 3C,D). The basolateral division also contained above control levels of labeling, particularly in the anterior and lateral nuclei (Fig. 3B). The posterior and basomedial posterior nuclei of the basolateral division were not reliably activated during exploration, although there was increased labeling of the basomedial anterior nucleus in about half of the animals (Fig. 3B,C). The central nucleus was conspicuous in having low levels of labeling relative to surrounding regions (Fig. 3A,B). Densitometric analyses of seven rats confirmed that labeling densities in the medial subdivision were substantially greater than those in the basolateral division and that hybridization in the central division was not significantly changed from control values (see Table 1).

The posterolateral cortical nucleus was variably labeled at different levels of the amygdala but the contiguous posteromedial cortical nucleus contained high levels of c-fos mRNA throughout its extent (Fig. 3D,E). Labeling in the bed nucleus of the stria terminalis was not noticeably greater than in surrounding areas and its subnuclei generally could not be differentiated in the autoradiographic material. A region at the ventromedial edge of the lateral ventricle did have unusually high levels of labeling (Fig. 3F). Whereas this may have overlapped the more superficial portions of the medial division of the bed nucleus, it was centered on the septohypothalamic nucleus.

\section{NOSE-POKING}

The intense activation of the medial amygdala found in the exploration rats was absent in animals

Table 1: Levels of $c$-fos $C R N A$ hybridization found in subdivisions of the amygdala across behaviors

\begin{tabular}{lccc}
\hline Group/region & Basolateral amygdala & Central amygdala & Medial amygdala \\
\hline Naive & $61 \pm 35$ & $40 \pm 18$ & $94 \pm 54$ \\
Exploration & $197 \pm 50^{* * *}$ & $38 \pm 32$ & $378 \pm 77^{* * *}$ \\
Nose-poke & $220 \pm 34^{* * *}$ & $99 \pm 16^{* *}$ & $190 \pm 46^{*}$ \\
Switch & $260 \pm 23^{* * *}$ & $76 \pm 57$ & $179 \pm 62^{*}$ \\
Overtrained & $114 \pm 22^{*}$ & $45 \pm 15$ & $116 \pm 36$ \\
\hline
\end{tabular}

Values are expressed in cpm/25 $\mu$ g of protein. Mean levels of hybridization found in the dentate gyrus molecular layer, which presumably contains only nonspecific labeling, were subtracted from mean levels of expression for each region and animal. Asterisks indicate significant differences from the naive group: $\left({ }^{*}\right) P<0.05 ;\left({ }^{* *}\right) P<0.01$; $\left.{ }^{(* *}\right) P<0.001$; StudentNewmann Keuls post hoc test.

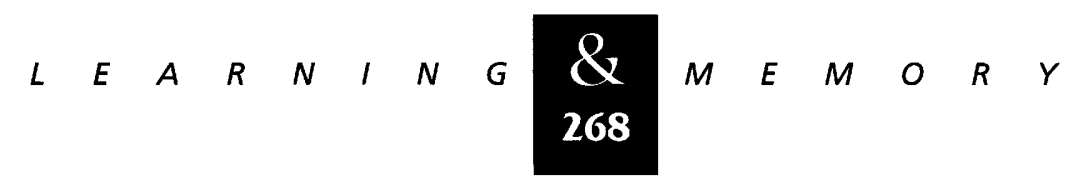


performing a well-learned nose-poke response for water rewards. As shown in Figure 4A, the anterior nucleus of the basolateral division was activated noticably and had levels of expression slightly greater than or equal to those in the medial division. The central nucleus, also unlike for exploration rats, had increased labeling in the nose-poke group; in two of six animals (Fig. 5C), there was elevated labeling in the lateral part of the central division. Quantitative analyses for the mid-anterior-posterior zone of the amygdala in six rats confirmed these observations. That is, values for the basolateral nuclei were significantly greater than those for controls, the medial nuclei had increased labeling modestly, and the central nuclei showed slightly elevated hybridization (see Table 1). Within-rat comparisons confirmed that the basolateral and medial nuclei had similar values with the former tending to be labeled more densely (the basolateral/medial expression ratio was 1.10 \pm 0.17 , mean \pm S.D., and was not significantly different than 1.00; two-tailed $t$-test). The relative balance of labeling in the basolateral versus central nuclei was significantly different from control, whereas the medial/central labeling ratio was not (Fig. 6).

As shown in Figure $4 \mathrm{C}$, the MePD was less densely labeled in caudal as compared with rostral planes (Fig. 4B). Figure 4 also illustrates the low levels of hybridization in the posterior and the basomedial nuclei of the basolateral division (Fig. $4 \mathrm{~A}, \mathrm{~B})$. This was similar to the pattern described for exploration rats (see Fig. 3B,C). The ventral baso- lateral nucleus had increased labeling in about half of the animals (Fig. $4 \mathrm{~B}, \mathrm{C}$ ). The posteromedial cortical nucleus contained moderate levels of c-fos mRNA (Fig. 4D) but in general this field was not as densely labeled as in the exploration group.

There was no differential activation of the bed nucleus of the stria terminalis in the nose-poke group (Fig. 4E), except in the one rat that had the greatest activation of the central amygdala (Fig. 5C). In this particular animal, increased labeling was observed in the lateral portion of the bed nucleus (Fig. 5D). The septohypothalamic nucleus was moderately densely labeled in a subgroup of the nose-poke rats. The case with greatest labeling is shown in Figure $4 \mathrm{E}$; note the discrete distribution of labeling and its occurrence in both the supra- and infracommissural segments of the nucleus. In most of the animals, however, the septohypothalamic nucleus was much less densely labeled than in the exploration rats.

\section{SWITCH TO CUED RESPONDING (ACQUISITION)}

Activation of the basolateral division that exceeded that in the medial division was a cardinal feature of rats required to switch from free to cued responding. The case shown in Figure $7 \mathrm{~A}$ demonstrates the extent to which labeling in the anterior component of the basolateral amygdala was elevated relative to levels in the medial and central divisions. Densitometric analyses confirmed these observations. Labeling of the basolateral division
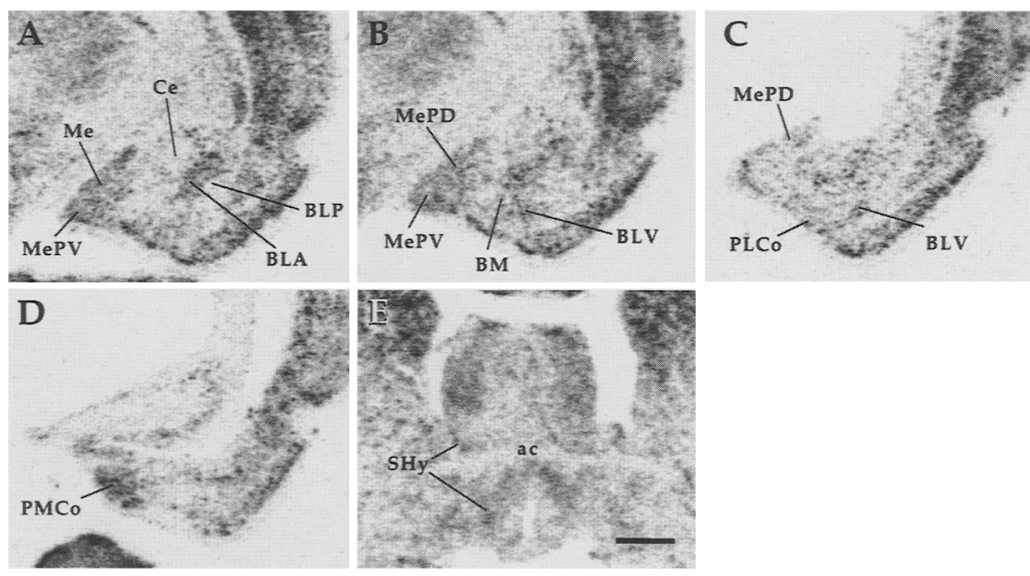

Figure 4: Computer-generated images of film autoradiographs showing c-fos cRNA labeling in the amygdala of a nosepoke rat $(A-D)$. Increased and comparable levels of hybridization are evident in the BLA and the medial division of the amygdala (including Me, MePV, and MePD shown here). The MePD is less densely labeled in caudal $(C)$ as compared with rostral planes $(B)$. The posteromedial cortical nucleus (PMCo; $D$ ) is moderately densely labeled, whereas the central nucleus (Ce) has little hybridization $(A)$. The septohypothalamic nucleus (SHy) is more densely labeled than surrounding tissue in a subgroup of nosepoke rats, the best case of which is illustrated in $E$ (both supra- and infracommissural segments are indicated). Bar, $1 \mathrm{~mm}$.

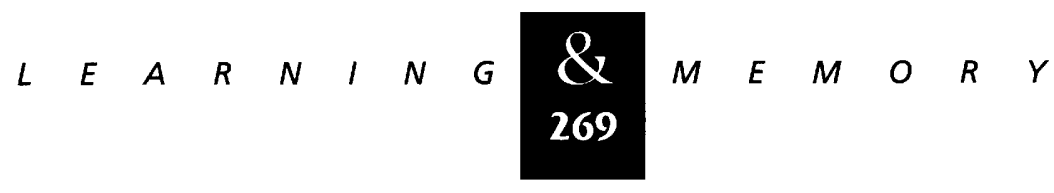


Hess et al.

Figure 5: Dark-field photomicrographs showing levels of c-fos cRNA hybridization in tissue sections through the central amygdala $(A, C)$ and the bed nucleus of the stria terminalis $(B, D)$ for a switch rat $(A, B)$ and a nose-poke rat $(C, D)$. These animals were chosen because they had the most striking labeling in the central amygdala of all the rats in their respective groups. As such, they are not representative, but rather illustrate a point. Whenever there was substantial labeling of the lateral central nucleus (arrows in $A$ and $C$ ), there was corresponding activation of the lateral part of the bed nucleus of the stria terminalis (arrowheads in $B$ and $D$ ). There also appeared to be a correlation between the intensity of labeling of the two structures. A similar correspondence between central amygdala and its anatomically defined counterpart in extended amygdala (i.e.,
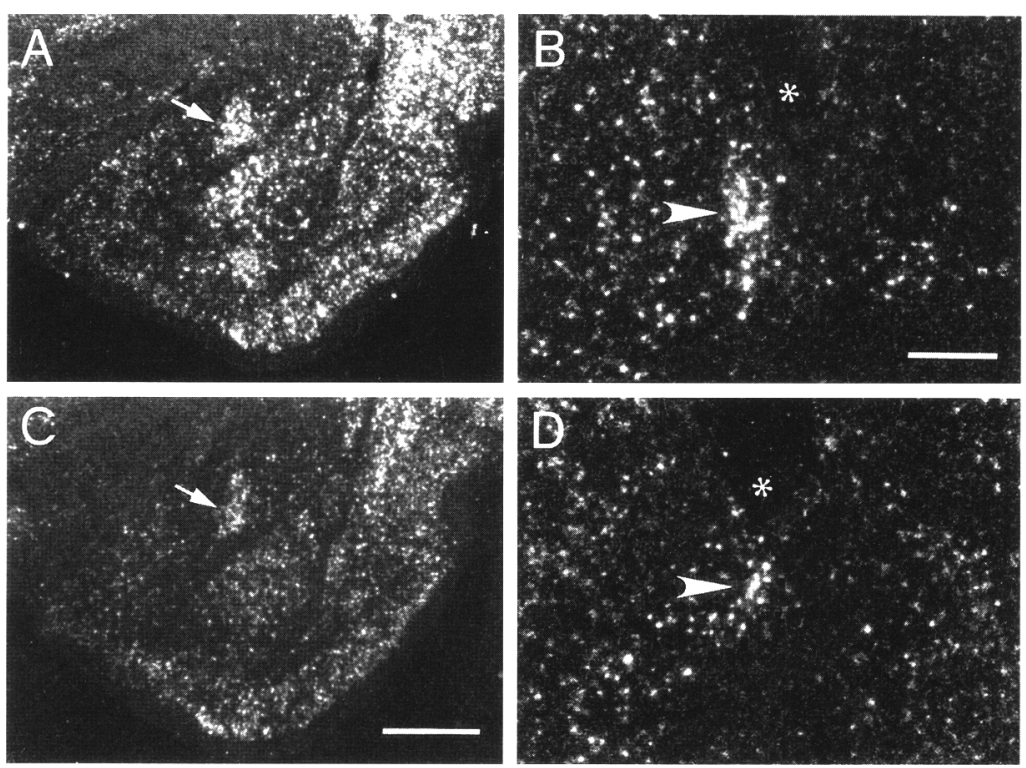
bed nucleus) was found in the injection/stress animals, although it was not always the case. The asterisks in $B$ and $D$ mark the lateral ventricles. The bar in $C$ (applies to $A$ and $C$ ), $925 \mu \mathrm{m}$. The bar in $B$ (applies to $B$ and $D$ ), $305 \mu \mathrm{m}$.

was substantially greater than that of the medial nuclei in each of six rats $(28 \pm 23 \%$, mean \pm s.D.; $P=0.03$, two-tailed one-sample $t$-test); this was despite a modest increase in medial labeling (Table 1) and was the reverse of the situation found in controls in which hybridization in the basolateral nuclei was less than that in the medial nuclei $(-12 \pm 6 \% ; P<0.001$, SNK post-hoc comparison with switch rats). Importantly, the basolateral/medial labeling ratio was also significantly different between the switch and nose-poke groups
$(P<0.05 ; \mathrm{SNK})$. As for nose-poke rats, the basolateral/central labeling ratio was significantly different from control, whereas the medial/central ratio was not (Fig. 6).

Hybridization within the basolateral complex in the switch group was not restricted to the anterior nucleus. Labeling in the lateral nuclei accompanied that in the basolateral anterior nucleus and appeared comparable in density. Furthermore, as shown in Figure 7 , the ventral basolateral nucleus was labeled to a greater degree than was the case

Figure 6: Bar graphs illustrating relative c-fos cRNA hybridization densities in the three divisions of the amygdala across successive stages of odor learning. The basolateral/medial expression ratio (BL/Me; left) was significantly less than control in exploration rats and significantly greater than control in nose-poke and switch rats. In addition, there was a notable change in this ratio with the transition from free to cued responding (i.e., nose-poking vs. switch; $P<0.05$, SNK post hoc comparison). When examining the basolateral/
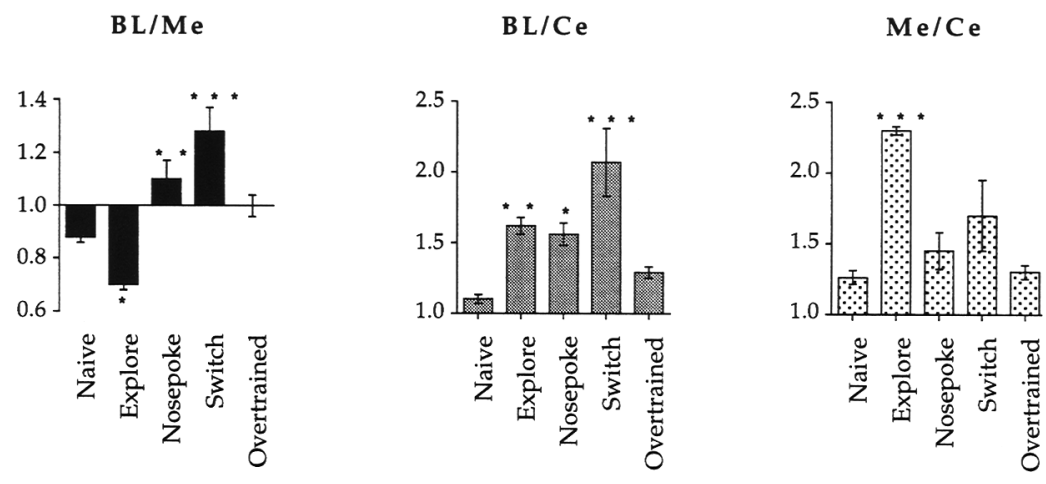
central (BL/Ce; center) and medial/central (Me/Ce; right) labeling ratios, it is further evident that the most distinctive shifts from control values are toward the basolateral nucleus in the switch animals and toward the medial nucleus in the exploration group. The $\mathrm{BL} / \mathrm{Ce}$ ratio was greater in the switch rats than in all other groups $(P<0.01, \mathrm{SNK})$, whereas the $\mathrm{Me} / \mathrm{Ce}$ ratio was increased dramatically in exploration rats relative to the other behavioral groups $(P<0.01, \mathrm{SNK})$. Asterisks indicate differences from cage control values; $\left({ }^{*}\right) P<0.05 ;\left({ }^{* *}\right) P<0.01 ;\left({ }^{* * *}\right) P<0.001$; SNK post hoc comparison.

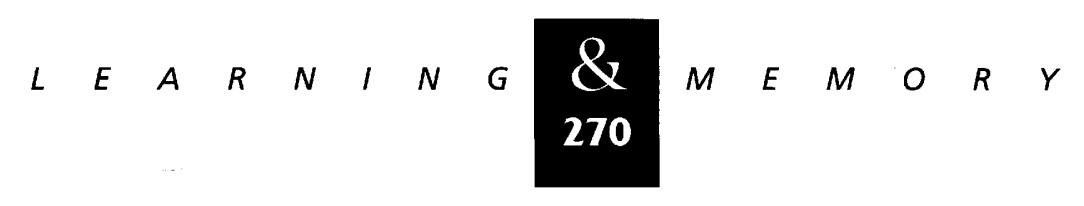



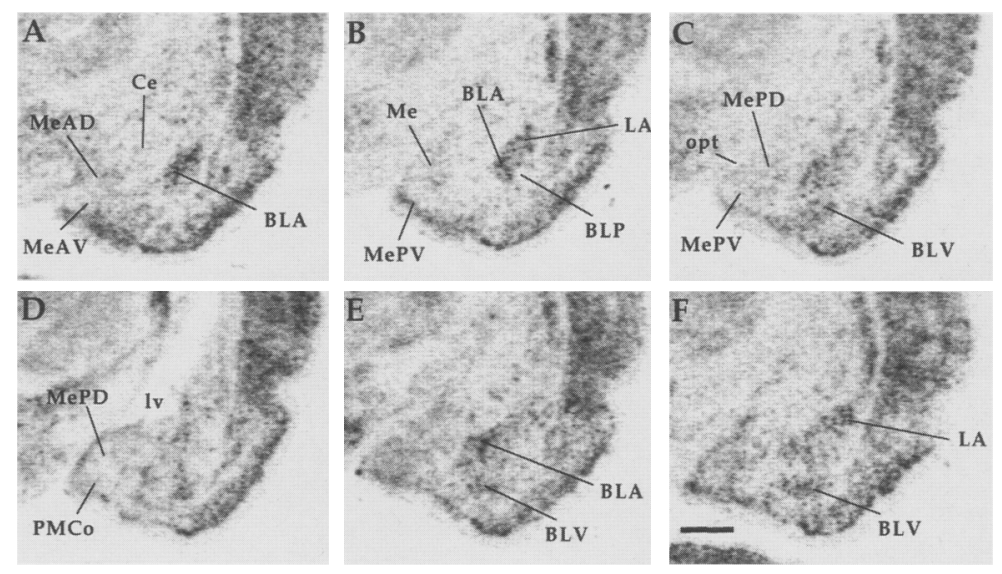

Figure 7: Film autoradiographs showing levels of c-fos cRNA labeling in switch rats. $(A-D)$ A rostrocaudal series of sections from one representative switch rat. Note the striking labeling of the basolateral division, particularly the BLA and LA nuclei, compared with surrounding structures $(A, B)$. Sections from two other switch rats $(E, F)$ illustrate further the point that the $B L V$ is labeled to a greater degree in switch rats than in other groups. Bar, $1 \mathrm{~mm}$.

for the other groups. The posterior segment of the basolateral nucleus had low levels of labeling (Fig. 7B). Hybridization densities were not reliably elevated in the posterior medial cortical nucleus in rats required to switch to cued responding.

Values for the central nucleus were not markedly different from control in switch rats (Table 1). But, as was the case for the nose-poke group, there was variability with two of six animals having some activation of the lateral sector of the central amygdala (Fig. 5A) and this labeling was even more striking than that seen in the nose-poke rats (Fig. 5C). Again, for these two rats there was a corresponding increase in labeling within the lateral parts of the bed nucleus of the stria terminalis (Fig. 5B). However, there was no reliable differential activation of the subdivisions of the bed nucleus in switch rats, and there was little labeling in the septohypothalamic nucleus (not shown).

\section{OVERTRAINED}

In well-trained rats performing a known odor discrimination, hybridization was low and relatively homogenous across the subdivisions of the amygdala. There were no obvious differences be- tween the basolateral and medial subdivisions at the mid anterior-posterior level (Fig. 8A,B). The within-rat ratio for the two nuclei was $1.00 \pm 0.08$ $(n=5)$ and the differences between them and the central nucleus also tended to be smaller than for the other behavioral groups (Table 1; Fig. 6). For instance, the basolateral/central labeling ratio was not different from control (Fig. 6). However, there was some labeling in the ventral basolateral and occasionally the basomedial nuclei (Fig. 8B), which was comparable with that in the anterior basolateral nucleus (Fig. 8A). Densitometric measurements confirmed these observations and showed that although labeling was not increased above control levels in the central or medial divisions, there was slightly greater hybridization in the basolateral nuclei (this difference just reached significance $P<0.05$, SNK, Table 1 ; however, when comparing the ratios of basolateral values with nonspecific labeling in the dentate gyrus molecular layer, there was only a trend for an increase).

Labeling was sparse in the posterior amygdala and the bed nucleus of the stria terminalis (Fig. $8 \mathrm{C})$. The paucity of labeling in the bed nucleus was conspicuous because of the moderate hybridization densities in surrounding structures; for ex-
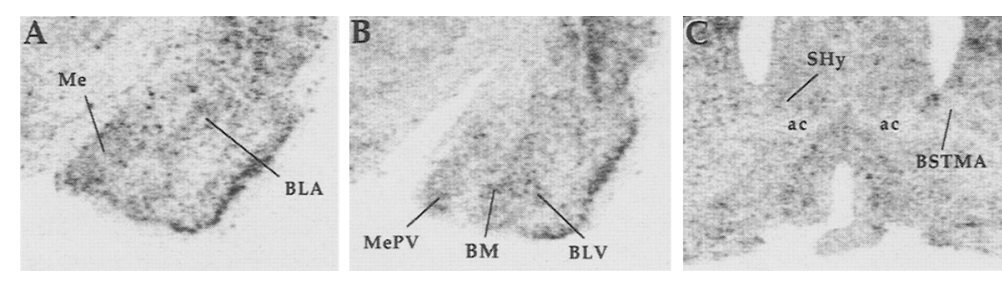

Figure 8: Film autoradiographs showing cfos CRNA hybridization in the amygdala $(A, B)$ and septum $(C)$ of representative overtrained rats. Note the low levels of labeling across subdivisions of the amygdala, and the comparably dense labeling of the medial and basolateral nuclei. In $C$, also note the low levels of expression in the septohypothalamic nucleus (SHy) and the medial anterior bed nucleus (BSTMA). Bar, $1 \mathrm{~mm}$.

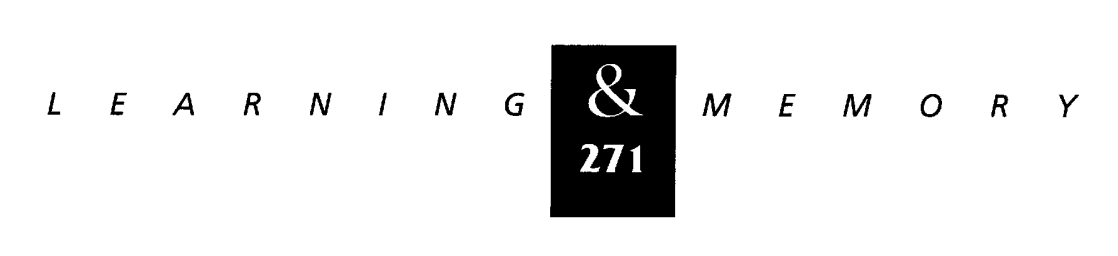


Hess et al.

ample, the septum at more rostral levels (data not shown).

Figure 6 shows the ratios of hybridization densities in the basolateral and medial nuclei, and of densities in these areas relative to the central nuclei. The most distinctive shifts from control values are toward the medial nucleus in the exploration group and toward the basolateral nucleus in the switch group. Figure 6 also illustrates the relatively small differences between the ratios found in overtrained rats and in home cage controls.

\section{COMPARISON CASES}

Two features of the amygdala common to animal groups at different stages of the learning paradigm were (1) little or no activation of the central nucleus, and (2) the absence of an intense, differentiated response in the components of the extended amygdala. This commonality could be attributable to the use of well-handled animals and the same behavioral apparatus for all groups. But it is also possible that the c-fos gene is not induced readily by neuronal activity in the areas exhibiting weak responses. Animals exposed to conditions very different than olfactory discrimination training were used to test the latter idea.

Sections through the amygdala of a previously handled rat given saline and cyclodextrin injections and allowed to explore an open-field apparatus are shown in Figure 9. An intense labeling in the central nucleus (lateral segment) with little response by the medial and basolateral divisions is apparent (Fig. 9A). This pattern was routinely encountered in injected rats and confirms earlier reports that c-fos is induced in the central nucleus by stressors (Hayward et al. 1990; Sharp et al. 1991;

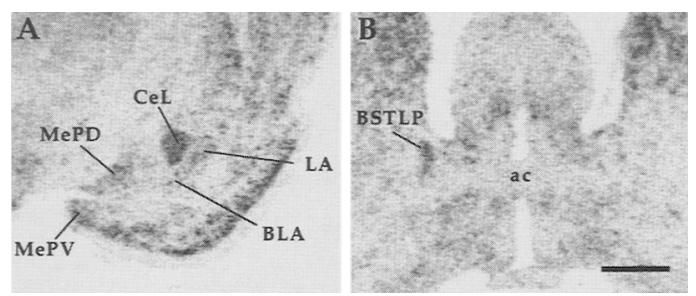

Figure 9: Film autoradiographs showing c-fos cRNA labeling in the amygdala $(A)$ and bed nucleus of the stria terminalis $(B)$ of a representative injection/stress rat. Note the dense hybridization in the lateral part of the central nucleus $(\mathrm{CeL} ; A)$ and in the lateral posterior portion of the bed nucleus (BSTLP; B). Bar, $1 \mathrm{~mm}$.
Duncan et al. 1993; Imaki et al. 1993; Sandner et al. 1993; Beck and Fibiger 1995). The response by the central nucleus was accompanied by activation of the lateral segment of the bed nucleus of the stria terminalis as shown in Figure 9B. This effect was regionally specific in that the other aspects of the bed nucleus did not appear to have elevated labeling. This pattern of c-fos expression is therefore reminiscent of the exceptional nose-poke and switch rats that also had corresponding, although weaker, activation of the central amygdala and the lateral portion of the bed nucleus.

Figure 10 shows sections through the mid-anterior-posterior level of the amygdala of a sexually experienced male rat that had been copulating. Intense activation of the medial subdivision is evident. Labeling was low in the ventral portions of the subdivision but extended to include its caudal nuclei (Fig. 10B-D). Therefore, copulatory behavior was associated with intense activation of the posterodorsal medial nucleus, a lesser response by the medial nucleus, and little reaction in the posteroventral nucleus. Exploration of the olfactory training apparatus, as described, elicited a complementary pattern; that is, comparable responses by the posteroventral and medial nuclei and weak activation of the posterodorsal nucleus. The tissue illustrated in Figure 10 also indicates that in the copulation rats labeling of the cortical amygdaloid nuclei differs from that in the olfactory learning groups. Specifically, in the copulation rats, the posterolateral cortical nucleus contained c-fos mRNA levels that were comparable with those in the posteromedial cortical nucleus (Fig. 10D,E); the posteromedial cortical nucleus was clearly dominant in the exploration group compared with more posterior portions of posterolateral cortical nucleus, as described above.

In the copulation rats, there was a striking and very selective response within the bed nucleus of the stria terminalis. The posterior segment of the medial division of the bed nucleus (BSTMP) was densely labeled, whereas the anterior segment was not; the lateral division (BSTL) was also not labeled prominently in these animals (Fig. 10F). As shown in Figure 9B, the responses of the bed nucleus to stress and copulation were complementary.

Figure 11 illustrates the differential labeling of the three divisions of the amygdala across behavioral circumstances. Dark-field photomicrographs of tissue autoradiographs are shown for rats of the switch, injection, exploration, and copulation groups. The relative differences in involvement of

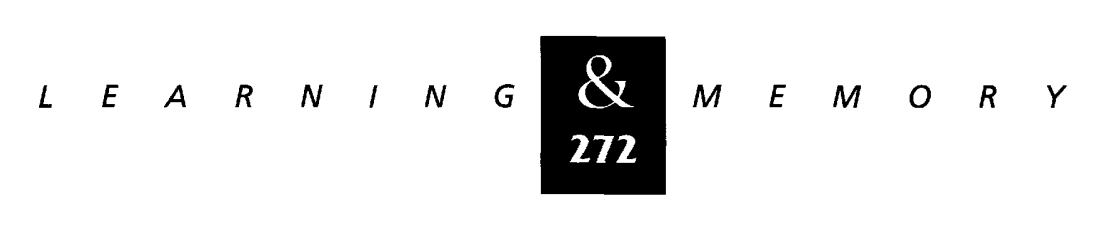



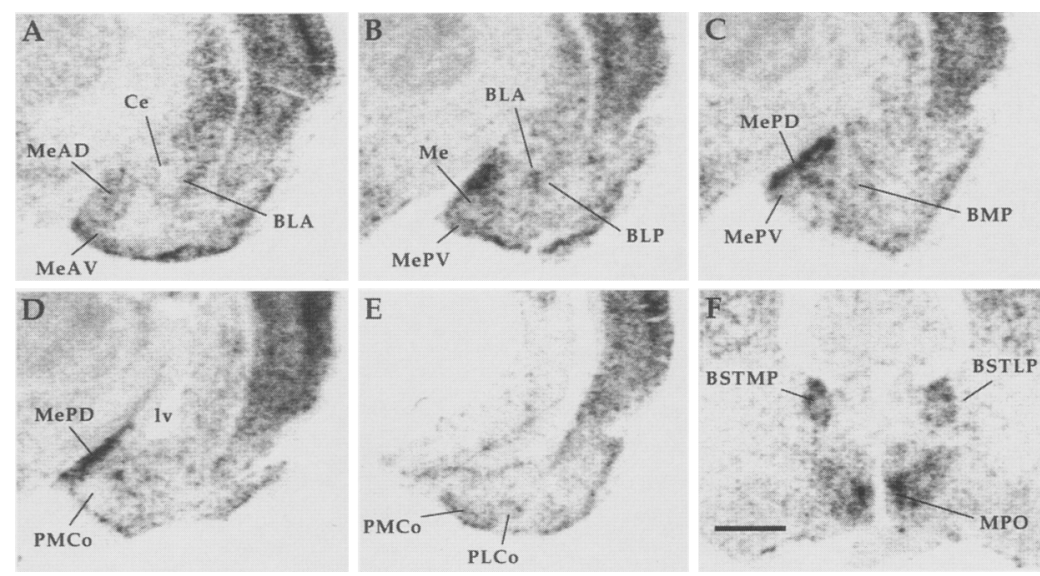

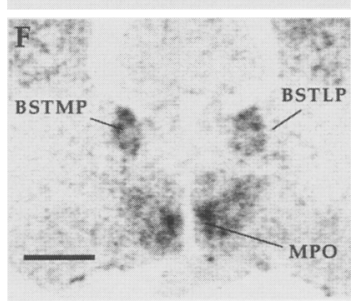

Figure 10: Computer-generated images of film autoradiographs showing levels of c-fos CRNA hybridization in a rostrocaudal series of sections through the amygdala of a representative copulation rat $(A-$ $E$ ). Note the dense labeling of nuclei of the medial division, particularly the MePD $(C, D)$. $(F)$ The corresponding activation of the medial posterior bed nucleus of the stria terminalis (BSTMP) and of the medial preoptic nucleus (MPO) in the same rat. Bar, $1 \mathrm{~mm}$. the divisions across conditions is especially striking in a side-by-side comparison.

\section{RELATIONSHIP TO CHANGES IN THE HIPPOCAMPUS}

Hippocampal subfields CA1, CA3, and dentate gyrus were sampled previously for the same animal treatment groups presented here. The data was
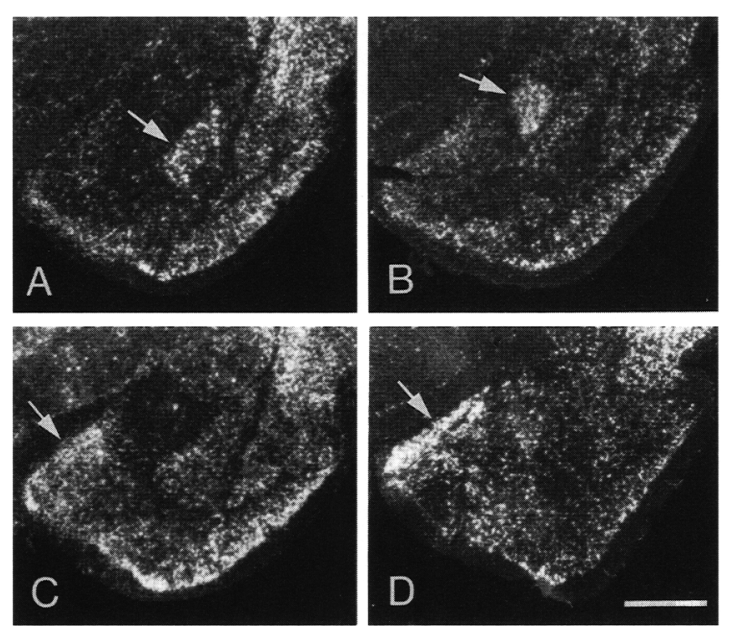

Figure 11: Dark-field photomicrographs of tissue autoradiographs showing levels of $c$-fos $C R N A$ labeling in the amygdala of representative switch $(A)$, injection $(B)$, exploration $(C)$, and copulation $(D)$ rats. Note the dense labeling in the basolateral division during switching (arrow in $A$ ), in the lateral part of the central nucleus after an injection (arrow in $B$ ), and in the medial division during exploration and copulation (arrows in $C$ and $D$, respectively). The patterns of hybridization in the medial division are distinct for the exploration and copulation rats. Bar, $1 \mathrm{~mm}$. normalized by subtracting tissue background and is presented in Table 2 . To provide a measure of the relative activity of amygdala versus hippocampus, the total of density measures for stratum granulosum and stratum pyramidale of fields CA3 and CA1 were expressed as a ratio of the total of density measures for the central, medial, and basolateral divisions (raw density measures, not normalized, were used for this ratio). The results (Fig. 12) indicate that relative to control rats the balance of labeling shifted to favor the hippocampus in the exploration and overtrained groups, but not in the nose-poke and switch groups. The similarity of hippocampal-to-amygdala ratios for the exploration and overtrained groups $(1.42 \pm 0.07$ vs. $1.43 \pm$ 0.06 , mean \pm S.E., respectively) is surprising given that absolute density measures are very different for the two groups.

Labeling density within CA1 was correlated with that in the basolateral nucleus to a greater or similar degree than with that in field CA3 for the exploration ( $r=0.70$ vs. $r=0.56$ ) and overtrained ( $r=0.86$ vs. $r=0.52$ ) groups, but not for the switch group ( $r=0.36$ vs. $r=0.81$ ). Correlations between the medial nucleus and the hippocampal subfields were generally weak. An exception was the task acquisition (switch) group in which field CA1 and the medial nucleus were correlated at $r=0.72$; this is of interest because of the absence of a correlation between CA1 and the basolateral nucleus in this group $(r=0.36)$. All amygdalar-hippocampal correlations are presented in Table 3 . Note the high degree of correlation between regions in the home cage control (naive) group. Presumably, c-fos mRNA levels in control rats are regulated by some generalized factor acting throughout much of the brain (e.g., arousal).

$$
\begin{array}{lllllllllllllllll}
\hline & E & A & R & N & I & N & G & \begin{array}{l}
\boldsymbol{X} \\
\mathbf{2 7 3}
\end{array} & M & E & M & O & R & Y
\end{array}
$$


Hess et al.

Table 2: Levels of c-fos CRNA hybridization in subdivisions of hippocampus across behaviors

\begin{tabular}{lccc}
\hline Group/region & \multicolumn{1}{c}{ CA1 } & CA3 & SG \\
\hline Naive & $89 \pm 57$ & $89 \pm 54$ & $84 \pm 18$ \\
Exploration & $587 \pm 83^{*}$ & $299 \pm 127^{*}$ & $246 \pm 57^{*}$ \\
Nose-poke & $271 \pm 30^{*}$ & $294 \pm 107^{*}$ & $100 \pm 42$ \\
Switch & $146 \pm 59$ & $341 \pm 107^{*}$ & $81 \pm 26$ \\
Overtrained & $360 \pm 108^{*}$ & $175 \pm 34$ & $104 \pm 36$ \\
\hline
\end{tabular}

Values are means \pm S.D. and are expressed in $\mathrm{cpm} / 25 \mu \mathrm{g}$ of protein. Mean levels of hybridization in the dentate gyrus molecular layer, which presumably contains only nonspecific labeling, were subtracted from mean levels of expression for each region and animal. Asterisks $\left({ }^{*}\right)$ indicate significant differences from the naive group at a level of $P<0.001$ (Student-Newmann Keuls post hoc test). (SG) Stratum granulosum.

\section{Discussion}

The above results provide evidence that the balances of activity across the amygdalar subdivisions, between the amygdala and its extension into the bed nucleus of the stria terminalis, and between the amygdala and hippocampus undergo significant changes as environmental demands shift. Certain of these changes are as expected

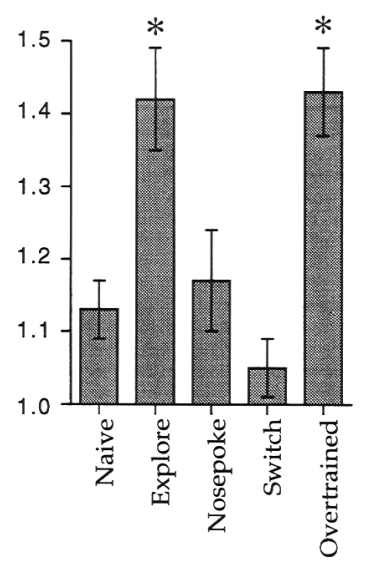

Figure 12: Bar graph illustrating relative levels of hybridization in hippocampus vs. amygdala for the various behavioral groups. The c-fos cRNA labeling densities in fields CA1, CA3, and stratum granulosum were summed and ratioed to total labeling in basolateral, medial, and central amygdala for animals at various stages of odor learning. In all groups, including naive rats, activation of the hippocampus was favored over the amygdala, although this difference was only slight for switch rats. Two circumstances led to a dramatic and similar increase in the hippocampal vs. the amygdalar response: exploration and overtraining. This was despite very different absolute levels of c-fos mRNA expression in hippocampus and amygdala of the two groups. $\left(^{*}\right) P<0.01$ compared with naive. from current ideas about the role of the amygdala in learning, whereas others have no obvious precedents. The results also show that some relationships recur at different stages of learning. Taken together the findings raise a number of questions concerning the nature of factors controlling the balance of activity within and between limbic circuitries and how shifts in these balances affect behavior. These issues will be considered within the context of the findings for each of the experimental groups.

\section{EXPLORATION}

Overall increases in c-fos mRNA levels were greatest in the rats that had just explored the olfactory testing apparatus. These animals were also unlike those in the other learning groups in that the balance of activity within the amygdala was clearly shifted in favor of the medial subdivision. Closer examination revealed that elevated c-fos expression within the division was restricted in that it involved the anterior, medial, and posteroventral nuclei but not the posterodorsal nucleus. The posterior cortical nuclei, which are usually grouped in the medial division, were also strongly activated during exploration. This occurred selectively: the posteromedial but not the posterolateral nucleus was densely labeled. The regional specificity for c-fos induction in the exploration group supports the argument, made on the basis of anatomical connections, that the medial division is composed of two quite distinct components, one centered on the posterodorsal nucleus and the other incorporating the anterior and posteroventral nuclei (Gomez and Newman 1992; Canteras et al. 1995). Previous work has established that the posterodorsal subdivision is sexually dimorphic (Hines et al.

$$
\text { , . . . n w }
$$


Table 3: Correlations of $c$-fos CRNA hybridization densities in the amygdalar subdivisions with those in subfields of hippocampus

\begin{tabular}{llcccc}
\hline $\begin{array}{l}\text { Group/correlation } \\
\text { coefficients }(r)\end{array}$ & Naive & Exploration & Nose-poke & Switch & Overtrained \\
\hline BL vs. CA1 & $0.88^{*}$ & 0.70 & 0.59 & 0.36 & 0.86 \\
BL vs. CA3 & $0.72^{*}$ & 0.56 & $0.85^{*}$ & $0.81^{*}$ & 0.52 \\
BL vs. SG & $0.90^{*}$ & 0.71 & $0.86^{*}$ & $0.93^{*}$ & $0.91^{*}$ \\
Me vs. CA1 & $0.92^{*}$ & 0.51 & 0.32 & 0.72 & 0.66 \\
Me vs. CA3 & $0.75^{*}$ & 0.24 & 0.40 & 0.58 & 0.66 \\
Me vs. SG & $0.90^{*}$ & 0.40 & 0.66 & 0.42 & 0.70 \\
Ce vs. CA1 & $0.85^{*}$ & 0.40 & 0.70 & 0.35 & 0.75 \\
Ce vs. CA3 & 0.55 & 0.26 & 0.79 & 0.57 & 0.85 \\
Ce vs. SG & $0.93^{*}$ & 0.40 & 0.64 & $0.85^{*}$ & 0.82 \\
\hline
\end{tabular}

The Pearson parametric correlation coefficients were calculated. Significant correlations are indicated with an asterisk (*two-tailed $P \leqslant 0.05$ ).

1992; for review, see Segovia and Guillamon 1993), enriched greatly with estrogen receptors relative to the remainder of the medial nuclei (Simerly et al. 1990), and has elevated concentrations of Fos protein in rats exposed to pheromonal cues (Bressler and Baum 1996). As described here, sexual behavior causes a pronounced increase in c-fos $\mathrm{mRNA}$ in the posterodorsal nucleus, a lesser response in the anterior nucleus, and little change in the posteroventral nucleus. Taken together, the near complementary c-fos results for copulation versus exploration add functional data to the anatomical arguments for subdividing the medial complex.

Despite the dense interconnections between the medial nuclei of the amygdala and the bed nucleus, intense activation of the former in the exploration group was not accompanied by an equivalent response in the appropriate subfields of the latter. It appears then that exploration creates imbalances between the poles of the extended amygdala. In contrast, sexual behavior resulted in responses that qualitatively at least appeared to be equal in the posterior portion of the medial division and its anatomically defined counterpart in the bed nucleus. A similar correspondence between amygdala (central nucleus) and extended amygdala (bed nucleus, lateral division) was found in the injection/stress rats and in a small subset of nose-poke and switch rats. Apparently, then, the balance varies across behaviors with exploration being a circumstance that favors the amygdala.

Although exploration did not elicit intense activity in the bed nucleus, it did trigger a response in the septohypothalamic nucleus (a portion of the ventral aspect of the lateral septum). Copulation did not appear to cause an equivalent effect. The septal region in question is a major target of the anterior (exploration) but not the posterodorsal (copulation) nucleus of the medial amygdala (Canteras et al. 1995); autoradiographic tracing studies indicate that it also receives input from the posterior cortical nucleus (Krettek and Price 1978), subfields of which had greater labeling in the exploration than the copulation group. In all then, the behavior specific pattern of c-fos expression for ventral lateral septum are in accord with neuroanatomical considerations.

The increases in amygdalar c-fos mRNA levels in the exploration animals, although pronounced, were exceeded by those in the hippocampus. Relative net activity (dentate $+\mathrm{CA} 3+\mathrm{CA} 1$ vs. medial + central + basolateral) shifted from $13 \%$ to $42 \%$ in favor of hippocampus from the home cage control to the exploration groups. This suggests that although the amygdala is intensely involved in the initial exploration of a novel environment, the hippocampus may assume a larger role in controlling behavior in such circumstances.

Regarding the nature of factors controlling the balance of activity within and between amygdaloid and limbic circuitries, the posterior cortical nuclei of the amygdala are densely innervated by bulbar projections and the medial division in general is a primary target of the olfactory system (de Olmos et al. 1985). It is reasonable to assume that odors are intensely sampled by rats learning a new environment, particularly one in which conspecific and novel olfactory cues had been present recently. 
These points could account for the proportionately greater response of the medial relative to the other divisions in the exploration group. Within the medial complex, the lack of a robust response in the posterodorsal nucleus follows from the presumed absence of pheromones and other explicit sex-related cues. The occurrence of strong responses in the posterior cortical, medial anterior, and posteroventral nuclei of the medial division but not in their counterparts in the bed nucleus provides one indicator of the degree to which reactions by densely interconnected anatomical systems need not develop in a stereotyped fashion but instead can be shaped by selective suppression of individual components. The failure of the bed nucleus to participate more obviously in the medial response was made striking by the activation of the neighboring ventral lateral septum (septohypothalamic nucleus) in the exploration animals, and it is intriguing to consider the possibility that these events are somehow linked. Possibly relevant to this, neuroanatomical studies have shown that the ventral lateral septum generates a strong projection to the rostral bed nucleus (Staiger and Nurnberger 1991) including zones targeted by the medial amygdala (Canteras et al. 1995), whereas physiological work points to a close relationship between the ventral lateral septum and the bed nucleus (Mathieson et al. 1989). The lateral septum, including its ventral aspect, contains high concentrations of GABAergic neurons (Kohler and Chan-Palay 1983; Panula et al. 1984; Jakab and Leranth 1990; and others), which would be expected to suppress responses by bed nucleus neurons to activity in the presumably glutamatergic medial amygdala (McDonald and Augustine 1993; Shindou et al. 1993; Pitkanen and Amaral 1994). According to this hypothesis, the weaker medial projection to the septum can serve, on some occasions, to cancel the effects of the stronger medial amygdalar projection to the bed nucleus (Canteras et al. 1995; see schematic in Fig. 13). The dominant response of the hippocampus may be the reason exploration is such an occasion. The temporal pole of hippocampus densely innervates the ventral lateral septum (Risold and Swanson 1996). Given that the hippocampal efferent neurons are extremely active in rats during exploration (Hess et al. 1995b), it can be assumed that during this behavior the excitatory hippocampal projection supplemented with output from the also active medial amygdala would increase neuronal firing in the ventrolateral septum.

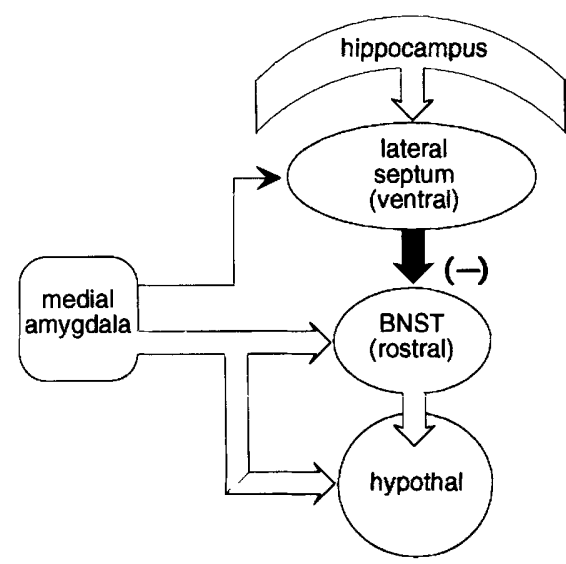

Figure 13: Schematic illustrating efferent projections from the medial amygdala to the ventral lateral septum (i.e., the septohypothalamic nucleus) and the bed nucleus of the stria terminalis (BNST) in the context of hippocampal and hypothalamic connections. As illustrated, the weaker medial amygdaloid projection to the septum may in some circumstances serve to cancel the effects of the stronger medial amygdaloid output to the bed nucleus. That is, activation of GABAergic neurons in the septum may suppress the activity of bed nucleus neurons, particularly in situations in which there is substantial activation of the temporal pole of hippocampus that also projects to the ventral lateral septum. These circumstances appear to arise in exploration rats in which there is elevated activation of the septohypothalamic nucleus, but no noticable labeling of the bed nucleus, despite the strong activation of the medial amygdala.

Related to the above is the question of why, in terms of telencephalic network operations, the hippocampus is so active during exploration, and to a degree, well in excess of the amygdala. Previous studies using emulsion autoradiography established that the hippocampal response does not occur uniformly across its subfields, but instead is characterized by small clusters of intensely labeled neurons in field CA1 and spotty labeling of discrete cells in stratum granulosum (Hess et al. 1995b). This is not unexpected given the observation that small numbers of hippocampal cells are used to encode locations and other spatiotemporal contingencies in the environment (Muller et al. 1987; Eichenbaum et al. 1989; Wiener et al. 1989; Barnes et al. 1990; Jung and McNaughton 1993); that is, that the cells are being driven by complex information arriving via the perforant path rather than by their more diffuse afferents from septum and lower brain. Exploration is apparently a circumstance in which intense scrutiny of the environ- 
ment leads to a great deal of the former type of input and a pattern of diffuse signals that favors high levels of pyramidal cell activity. In this sense, exploration of a novel environment may, almost by definition, give rise to an unusually large amount of input to the hippocampus; as with olfactory cues and the medial amygdala, this could be sufficient to trigger a pronounced response. How the relative balance of activity between hippocampus and amygdala is set is a topic that is better considered after consideration of the results for the other groups.

The amygdala has extensive interconnections with the hypothalamus and activity in that region is perhaps the most obvious starting point for a consideration of the functional/behavioral consequences of the imbalances described above. The bed nucleus and amygdaloid components of the extended amygdala have overlapping targets in the hypothalamus and rostral brainstem (Alheid and Heimer 1996). Presumably then, a failure to activate the bed nucleus portion of the medial or central extended amygdala would result in a less than maximal hypothalamic response. Qualitative comparisons of the exploration rats with those in the copulation and injection/stress groups support this idea. That is, the intensity and differentiation of the hypothalamic c-fos pattern covaried with the degree of activation in the bed nucleus across the three groups. Although this could mean that high levels of activity in the hypothalamus are necessary for a bed nucleus response to emerge, it is also consonant with the idea that conjoint activation of the amygdaloid and bed nuclear portions of the extended amygdala are prerequisites for eliciting a strong and distinct response by the hypothalamus. The medial hypothalamic zones innervated by the anterior and posteroventral nuclei of the medial amygdala (de Olmos et al. 1985) project densely into the periaqueductal gray (Simerly and Swanson 1986, 1988; Rizvi et al. 1992; Canteras et al. 1994; Risold et al. 1994; and others) and have been proposed to generate reproductive and agonistic behaviors (Canteras et al. 1994, 1995; Risold et al. 1994). If so, then the imbalances in the components of the extended medial amygdala could serve to prevent a collection of lower brain behaviors from coming into play during exploration.

\section{NOSE-POKING}

The sharply differentiated pattern of activity found in the amygdala of exploration rats was not present in animals performing a well-rehearsed nose-poke response. Specifically, the medial and basolateral divisions had similar labeling intensities whereas even the central nuclei had somewhat elevated expression levels compared with controls, which was unique among the behavioral groups. It is noteworthy that the various aspects of the bed nucleus and the posterior cortical nuclei also did not exhibit a reliable, differentiated response in nose-poke rats. Hippocampal subfields CA1 and CA3 were activated roughly equivalently in the nose-poke animals (Hess et al. 1995a) and the ratio of net activity in hippocampus to that in the amygdala is close to that found in home cage controls. These observations point to the conclusion that the limbic system makes a global, generalized contribution to the regulation of ad libitum responding. This accords with reports that lesions to hippocampus or amygdala have relatively minor effects on well-learned, simple responses (Slotnick and Kaneko 1981; Fagan et al. 1985; Slotnick 1985; Eichenbaum et al. 1986; Staubli et al. 1986, 1989; Parent et al. 1994, 1995). It will be of considerable interest in future studies to determine if the rather uniform response of the limbic telencephalon is accompanied by highly differentiated response profiles in other brain systems. Preliminary analyses of hypothalamus have confirmed this expectation (U.S. Hess, C.M. Gall, and G. Lynch, unpubl.).

\section{SWITCHING FROM AD LIBITUM TO CUED RESPONDING}

The predominant and pronounced activation of the basolateral division in the switch group was one of the more striking effects obtained in the present study. This result is consonant with current hypotheses positing a role for the basolateral complex in attaching valences to distant cues (LeDoux 1993a,b; Davis et al. 1994; Ono et al. 1995) or in modulating the processes whereby such assignments are made (McGaugh et al. 1993, 1996; Cahill and McGaugh 1996). It is interesting in this regard that, to date, studies that have looked at amygdala involvement in odor discrimination have yielded largely negative results (Slotnick and Kaneko 1981; Fagan et al. 1985; Slotnick 1985; Eichenbaum et al. 1986). Anterior amygdala lesions did not impair odor discrimination (Slotnick 1985), nor did bilateral amygdala damage interfere with learning set acquisition (Fagan et al. 1985; Eichenbaum et al. 1986). All of these studies used succes-

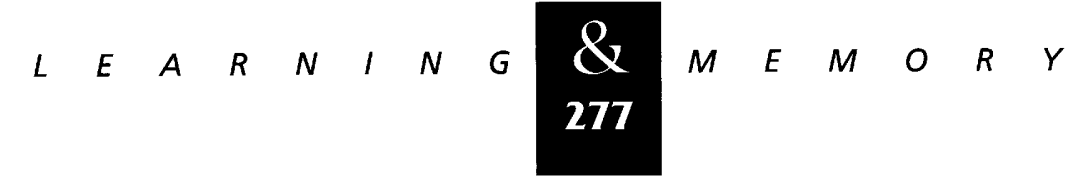


Hess et al.

sive-cue learning with no negative reinforcement. However, complex lesions of the amygdala have been shown to affect retention of tasks differentially using appetitive and aversive reinforcement (Cahill and McGaugh 1990). It is possible, that it was the need to simultaneously assign positive and negative valences to distal cues in the present study that led to the strong involvement of the basolateral nucleus during acquisition of the odor pair.

Our findings provide no clues, however, pertinent to the critical question of how the center of activation in the amygdala is switched from the medial to the basolateral nuclei in the switch group. One possibility is a change in the activity of the ascending monoaminergic systems that densely innervate the amygdala (de Olmos et al. 1985). If, as generally thought, activity in these ascending systems is influenced strongly by motivation and reward, then it would not be surprising that a change in reward contingencies is associated with a change in the pattern of regional activation within the amygdala. Also of interest in this regard is the previous finding that $\mathrm{CA} 3$ becomes the dominant hippocampal subfield only in the switch rats (Hess et al. 1995a). The consequence of this would be to shift the primary hippocampal outflow toward the lateral septum and away from the retrohippocampal cortex (Swanson and Cowan 1977; Van Groen and Wyss 1990; Amaral and Witter 1995). Given that the former, largely GABAergic structure imposes an inhibitory influence on the bed nucleus, the hippocampal pattern could act to suppress an important input to the medial and central but not basolateral divisions of the amygdala.

A shift in the balance of activation from medial to basolateral amygdala corresponds to shifting the predominant outflow of the amygdala away from the hypothalamus and toward frontal cortex. It is curious that the reverse trend occurs in hippocampus; that is, through the first three stages of training (exploration, nose-poking, switching) there is a shift in relative output toward the septum and hypothalamus and away from striatal and frontal targets. Together these effects suggest that the change from ad libitum nose-poking to cued responding involves emphasizing the influence of amygdala on the cortex/striatum at the expense of hippocampus. This point can be made quantitatively by comparing the ratios for basolateral amygdala with hippocampal CA1 across the different groups in the study. As seen in Figure 14, the values for the switch rats are strikingly different from those for the animals in the other groups and indicate the extent to which relative activity in the two pathways leading to the striatum has changed in favor of the amygdala. It will be of interest to determine if the frontal/striatal circuitries shown by Groenewegen and colleagues to be connected intimately with the basal amygdala (Groenewegen et al. 1990; Wright and Groenewegen 1995; Wright et al. 1996) are increased in activity above similar networks with close ties to the hippocampus.

\section{OVERTRAINED}

Labeling of the basolateral amygdala was lower in both absolute and relative terms in the overtrained rats compared with those in the switch group and differences between the three divisions were not much greater than those found in home cage controls. It was suggested earlier that withholding expected rewards, as occurs in the switch condition, would alter the activity of monoaminergic afferents and via this route adjust the relative activity of the basolateral nuclei. Analyses of the raphe nuclei, locus coeruleus, ventral tegmental area, and basal forebrain could provide clues about the plausibility of the argument regarding the role of the ascending, diffuse systems in regulating the
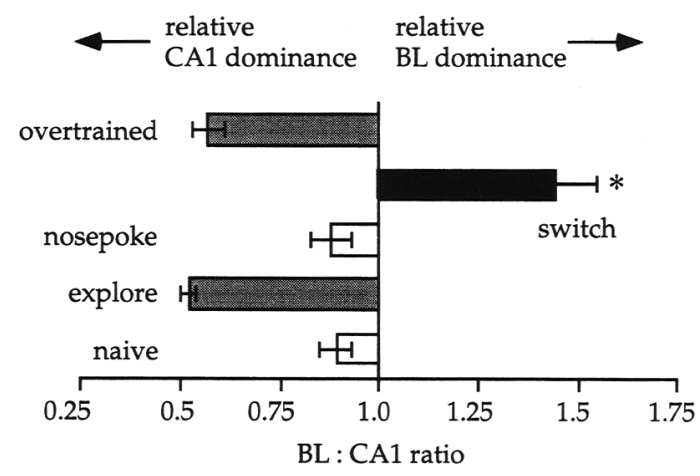

Figure 14: Bar graph illustrating relative levels of c-fos mRNA expression in basolateral amygdala vs. hippocampal subfield CA1 for the various groups. Most notably, switch rats were unique in terms of having a relative basolateral (BL) dominance, whereas the exploration and overtrained animals had a relative CA1 dominance. Nose-poke rats were similar to controls. The basolateral amygdala and field CA1 project to distinct fields within striatum and cortex. The BL dominance therefore seems to be a special circumstance favoring amygdalar influence over these regions during the formation of associations between odors and postive/negative rewards. $\left({ }^{*}\right)$ $P<0.001$ compared with all other groups.

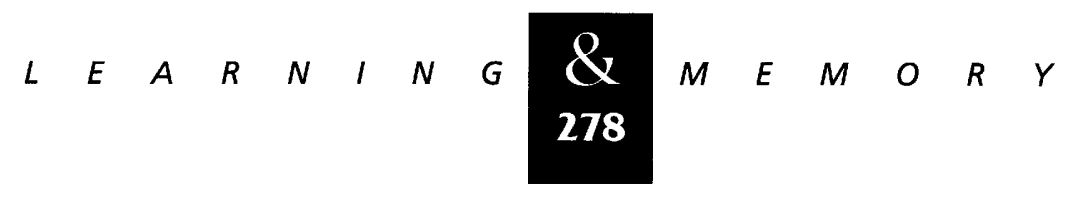


excitability of the basolateral region. The hypothesis also predicts that, other things being equal, the basolateral nuclei will have relatively low levels of activity in circumstances in which expected rewards are nearly always obtained. The overtrained rats, which select the incorrect odor in fewer than $15 \%$ of their trials, do in fact have an extremely reliable reward system. Whereas these observations are supportive of the idea that failure of expected events is one factor that enhances activity in the basolateral amygdala, explicit tests need to be made using overtrained rats working on different reinforcement schedules. With regards to this, it has been suggested previously that the basolateral/lateral complex is involved in learning about, or expressing the response to, the aversiveness of reward reduction (Salinas et al. 1993, 1996).

Less basolateral activity was accompanied by a marked activation of hippocampal subfield CA1. The progression from initial acquisition of the task to overtrained was therefore characterized by a dramatic shift in the balance of activity between the two limbic pathways leading to the striatum and cortex from amygdala dominant to hippocampal dominant. In quantitative terms, the basolateral/CA1 ratio changed from $1.44 \pm 0.11$ in the switch group to $0.57 \pm 0.04$ in the overtrained group (mean \pm S.E.; see Fig. 14, above). Preliminary examinations suggest that patterns of c-fos expression in the medial and orbital regions of frontal cortex in overtrained rats differ from those of switch animals (U.S. Hess, C.M. Gall, and G. Lynch, unpubl.). This is encouraging with regard to the above noted possibility of identifying functionally distinct amygdala-frontal-striatal versus hippocampo-frontal-striatal circuits.

Two types of information are useful in considering the potential behavioral significance of shifts in the amygdala/hippocampal ratio: (1) the broader collection of network activity patterns associated with each ratio and (2) the types of behavior in which a given balance is observed. Concerning the latter, the amygdala/hippocampal and basolateral/CA1 ratios for the overtrained rats were very close to those of the exploration group. The behaviors exhibited by rats in the two groups have little in common except attention and reaction to distant cues. In the case of exploration, animals spend considerable time rearing, a complex activity essential to the sampling of an array of visual and olfactory cues. Overtrained rats enter the apparatus from a start point, pause, sample two simultaneously present odors, localize their ori- gins, and then respond (for description, see Larson et al. 1995). These behaviors bear little resemblance to the local cue-local response interactions of the nose-poke animals or the agitation exhibited by the rats required to suppress free responding and begin attending to odors.

\section{CONCLUSION}

It has become increasingly clear that the amygdala cannot be viewed as a unitary structure, but rather that its many nuclei, with distinct inputouput connections, are engaged in diverse functions. The present results, demonstrating differential activation of the various subdivisions of the amygdala across sequential stages of odor learning, underline this conclusion. The results demonstrate that the balance of activity within and between limbic structures shifts according to demands placed on behavior and that certain relationships recur across seemingly different behaviors. It is suggested that these balances reflect, among other factors, availability of pertinent afferent cues, interactions between hippocampus and the extended amygdala mediated by the lateral septum, and relative levels of activity in the diffuse (cholinergic, serotoninergic, etc.) projections to the limbic system.

\section{Acknowledgments}

We thank Thömas Nguyen and Julie Wong for assistance in training animals and Ben Tran for help in data analysis. We also thank Dr. Larry Cahill for helpful discussions. This research was supported by grant HD24236 and Research Scientist Development Award MH00974 to C.M.G., grant 00014-89-J-1255 from the Office of Naval Research and a Research Scientist Award MH00358 to G.L., and National Institute of Mental Health predoctoral fellowship MH10510 to U.S.H.

The publication costs of this article were defrayed in part by payment of page charges. This article must therefore be hereby marked "advertisement" in accordance with 18 USC section 1734 solely to indicate this fact.

\section{References}

Alheid, G.F. and L. Heimer. 1988. New perspectives in basal forebrain organization of special relevance for neuropsychiatric disorders: The striatopallidal, amygdaloid and corticopetal components of substantia innominata. Neuroscience 27: 1-39.

1996. Theories of basal forebrain organization and the "emotional motor system". Prog. Brain Res. 107: 461-484.

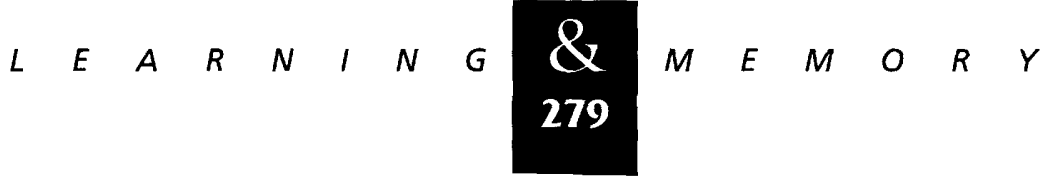


Hess et al.

Alheid, G.F., J.S. de Olmos, and C.A. Beltramino. 1995. Amygdala and extended amygdala. In The rat nervous system (ed. G. Paxinos), pp. 495-578. Academic Press, San Diego, CA.

Amaral, D.G. and M.P. Witter. 1995. Hippocampal formation. In The rat nervous system (ed. G. Paxinos), pp. 443-493. Academic Press, San Diego, CA.

Barnes, C.A., B.L. McNaughton, S.J. Mizumori, B.W. Leonard, and L.H. Lin. 1990. Comparison of spatial and temporal characteristics of neuronal activity in sequential stages of hippocampal processing. Prog. Brain Res. 83: $287-300$.

Beck, C.H. and H.C. Fibiger. 1995. Conditioned fear-induced changes in behavior and in the expression of the immediate early gene c-fos: With and without diazepam pretreatment. J. Neurosci. 15: 709-720.

Bernard, J.F., H. Bester, and J.M. Besson. 1996. Involvement of the spino-parabrachio-amygdaloid and -hypothalamic pathways in the autonomic and affective emotional aspects of pain. Prog. Brain Res. 107: 243-255.

Bialy, M. and L. Kaczmarek. 1996. c-Fos expression as a tool to search for the neurobiological base of the sexual behaviour of males. Acta Neurobiol. Exp. 56: 567-577.

Bressler, S.C. and M.J. Baum. 1996. Sex comparison of neuronal Fos immunoreactivity in the rat vomeronasal projection circuit after chemosensory stimulation.

Neuroscience 71: 1063-1072.

Burns, L.H., B.J. Everitt, and T.W. Robbins. 1994. Intra-amygdala infusion of the $\mathrm{N}$-methyl-D-aspartate receptor antagonist AP5 impairs acquisition but not performance of discriminated approach to an appetitive CS. Behav. Neural Biol. 61: 242-250.

Cador, M., T.W. Robbins, and B.J. Everitt. 1989. Involvement of the amygdala in stimulus-reward associations: Interaction with the ventral striatum. Neuroscience 30: 77-86.

Cahill, L. and J. McGaugh. 1990. Amygdaloid complex lesions differentially affect retention of tasks using appetitive and aversive reinforcement. Behav. Neurosci. 104: 532-543.

1996. Modulation of memory storage. Curr. Opin.

Neurobiol. 6: 237-242.

Canteras, N.S., R.B. Simerly, and L.W. Swanson. 1994. Organization of projections from the ventromedial nucleus of the hypothalamus: A Phaseolus vulgaris-leucoagglutinin study in the rat. J. Comp. Neurol. 348: 41-79.

1995. Organization of projections from the medial nucleus of the amygdala: A PHAL study in the rat. J. Comp. Neurol. 360: 213-245.

Curran, T., M.B. Gordon, K.L. Rubino, and L.C. Sambucetti. 1987. Isolation and characterization of the $c$-fos (rat) CDNA and analysis of post-translational modification in vitro. Oncogene 2: 79-84.

Davis, M., D. Rainnie, and M. Cassell. 1994. Neurotransmission in the rat amygdala related to fear and anxiety. Trends Neurosci. 17: 208-214.

de Olmos, J.S., G.F. Alheid, and C.A. Beltramino. 1985. Amygdala. In The rat nervous system: Forebrain and midbrain (ed. G. Paxinos), pp. 223-334. Academic Press, San Diego, CA.

Duncan, G.E., K.B. Johnson, and G.R. Breese. 1993. Topographic patterns of brain activity in response to swim stress: Assessment by 2-deoxyglucose uptake and expression of Fos-like immunoreactivity. J. Neurosci. 13: 3932-3943.

Dunn, J.D. and J. Whitener. 1986. Plasma corticosterone responses to electrical stimulation of the amygdaloid complex: Cytoarchitectural specificity. Neuroendocrinology 42: $211-217$.

Eichenbaum, H., A. Fagan, and N. Cohen. 1986. Normal olfactory discrimination learning set and facilitation of reversal learning after medial-temporal damage in rats: Implications for an account of preserved learning abilities in amnesia. J. Neurosci. 6: 1876-1884.

Eichenbaum, H., S.l. Wiener, M.L. Shapiro, and N.J. Cohen. 1989. The organization of spatial coding in the hippocampus: A study of neural ensemble activity. J. Neurosci. 9: 2764-2775.

Everitt, B., K. Morris, A. O'Brien, and T. Robbins. 1991. The basolateral amygdala-ventral striatal system and conditioned place preference: Further evidence of limbic-striatal interactions underlying reward-related processes. Neuroscience 42: 1-18.

Everitt, B.J., M. Cador, and T.W. Robbins. 1989. Interactions between the amygdala and ventral striatum in stimulus-reward associations: Studies using second-order schedule of sexual reinforcement. Neuroscience 30: 63-75.

Fagan, A., H. Eichenbaum, and N. Cohen. 1985. Normal learning set and facilitation of reversal learning in rats with combined fornix-amygdala lesions: Implications for preserved learning abilities in amnesia. Ann. NY Acad. Sci.

444: 510-512.

Fernandez-Fewell, G.D. and M. Meredith. 1994. C-fos expression in vomeronasal pathways of mated or pheromone-stimulated male golden hamsters: Contributions from vomeronasal sensory input and expression related to mating performance. J. Neurosci. 14: 3643-3654.

Flanagan-Cato, L.M. and B.S. McEwen. 1995. Pattern of Fos and Jun expression in the female rat forebrain after sexual behavior. Brain Res. 673: 53-60.

Gaffan, D. and S. Harrison. 1987. Amygdalectomy and disconnection in visual learning for auditory secondary reinforcement by monkeys. J. Neurosci. 7: 2285-2292.

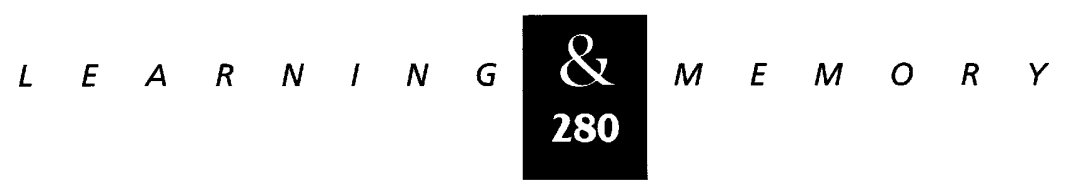


Gall, C., K. Murray, and P.J. Isackson. 1991. Kainic acid-induced seizures stimulate increased expression of nerve growth factor mRNA in rat hippocampus. Mol. Brain Res. 9: 113-123.

Gall, C., J. Lauterborn, and K. Guthrie. 1995. In situ hybridization: A sensitive measure of activity-dependent changes in neuronal gene expression. In Autoradiography and correlative imaging (ed. W.E. Stumpf and H.F. Solomon) pp. 379-399. Academic Press, San Diego, CA.

Gall, C.M., R. Berschauer, and P.J. Isackson. 1994. Seizures increase basic fibroblast growth factor mRNA in adult rat forebrain neurons and glia. Mol. Brain Res. 21: 190-205.

Gomez, D.M. and S.W. Newman. 1992. Differential projections of the anterior and posterior regions of the medial amygdaloid nucleus in the Syrian hamster. J. Comp. Neurol. 317: 195-218.

Groenewegen, H.J., H.W. Berendse, J.G. Wolters, and A.H. Lohman. 1990. The anatomical relationship of the prefrontal cortex with the striatopallidal system, the thalamus and the amygdala: Evidence for a parallel organization. Prog. Brain Res. 85: 95-116; Discussion 116-118.

Harris, V.S. and B.D. Sachs. 1975. Copulatory behavior in male rats following amygdaloid lesions. Brain Res.

86: $514-518$.

Hatfield, T., J.S. Han, M. Conley, M. Gallagher, and P. Holland. 1996. Neurotoxic lesions of basolateral, but not central, amygdala interfere with Pavlovian second-order conditioning and reinforcer devaluation effects. J. Neurosci. 16: 5256-5265.

Hayward, M.D., R.S. Duman, and E.J. Nestler. 1990. Induction of the c-fos proto-oncogene during opiate withdrawal in the locus coeruleus and other regions of rat brain. Brain Res. 525: 256-266.

Heeb, M.M. and P. Yahr. 1996. c-Fos immunoreactivity in the sexually dimorphic area of the hypothalamus and related brain regions of male gerbils after exposure to sex-related stimuli or performance of specific sexual behaviors. Neuroscience 72: 1049-1071.

Hess, U.S., G. Lynch, and C.M. Gall. 1995a. Changes in c-fos mRNA expression in rat brain during odor discrimination learning: Differential involvement of hippocampal subfields CA1 and CA3. J. Neurosci. 15: 4786-4795.

1995b. Regional patterns of c-fos mRNA expression in rat hippocampus following exploration vs. performance of a well-learned discrimination. J. Neurosci. 15: 7796-7809.

Hines, M., L.S. Allen, and R.A. Gorski. 1992. Sex differences in subregions of the medial nucleus of the amygdala and the bed nucleus of the stria terminalis of the rat. Brain Res. 579: $321-326$.

Imaki, T., T. Shibasaki, M. Hotta, and H. Demura. 1993.
Intracerebroventricular administration of corticotropin-releasing factor induces $c$-fos mRNA expression in brain regions related to stress responses: Comparison with pattern of $c$-fos mRNA induction after stress. Brain Res. 616: $114-125$.

Jakab, R.L. and C. Leranth. 1990. Catecholaminergic, GABAergic, and hippocamposeptal innervation of GABAergic "somatospiny" neurons in the rat lateral septal area. J. Comp. Neurol. 302: 305-321.

Jung, M.W. and B.L. McNaughton. 1993. Spatial selectivity of unit activity in the hippocampal granular layer. Hippocampus 3: 165-182.

Kato, M., T. Kakegawa, and M. Suzuki. 1986. Electrical stimulation of several limbic areas suppressed the growth hormone $(\mathrm{GH})$ release induced by human pancreatic GH-releasing factor in pentobarbital-anesthetized rats. Endocrinology 118: 955-960.

Kirouac, G.J. and P.K. Ganguly. 1995. Topographical organization in the nucleus accumbens of afferents from the basolateral amygdala and efferents to the lateral hypothalamus. Neuroscience 67: 625-630.

Kohler, C. and V. Chan-Palay. 1983. Distribution of gamma aminobutyric acid containing neurons and terminals in the septal area. An immunohistochemical study using antibodies to glutamic acid decarboxylase in the rat brain. Anat. Embryol. 167: 53-65.

Krettek, J.E. and J.L. Price. 1978. Amygdaloid projections to subcortical structures within the basal forebrain and brainstem in the rat and cat. J. Comp. Neurol. 178: 225-254.

Larson, J., T. Lieu, V. Petchpradub, B. LeDuc, H. Ngo, G.A. Rogers, and G. Lynch. 1995. Facilitation of olfactory learning by a modulator of AMPA receptors. J. Neurosci.

15: 8023--8030.

Lauterborn, J.C., P.J. Isackson, R. Montalvo, and C.M. Gall. 1993. In situ hybridization localization of choline acetyltransferase mRNA in adult rat brain and spinal cord. Mol. Brain Res. 17: 59-69.

LeDoux, J.E. 1992. Emotion and the amygdala. In The amygdala: Neurobiological aspects of emotion, memory, and mental dysfunction (ed. J.P. Aggelton), pp. 339-351. Wiley-Liss Publishers, New York, NY.

1993a. Emotional memory: In search of systems and synapses. Ann. N.Y. Acad. Sci. 702: 149-157.

1993b. Emotional memory systems in the brain. Behav. Brain Res. 58: 69-79.

Liang, K.C., W. Hon, and M. Davis. 1994. Pre- and posttraining infusion of $\mathrm{N}$-methyl-D-aspartate receptor antagonists into the amygdala impair memory in an inhibitory avoidance task. Behav. Neurosci. 108: 241-253.

Luiten, P.G., J.M. Koolhaas, S. de Boer, and S.J. Koopmans.

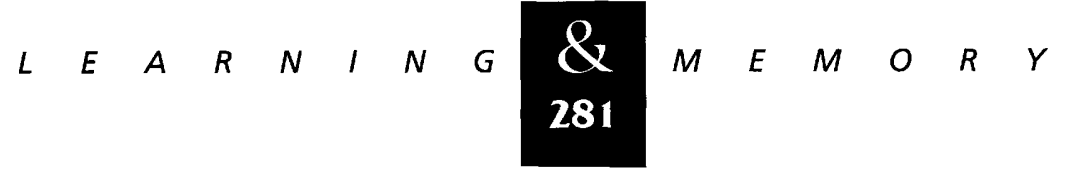


1985. The cortico-medial amygdala in the central nervous system organization of agonistic behavior. Brain Res. 332: $283-297$.

Maeda, H., H. Morimoto, and K. Yanagimoto. 1993. Response characteristics of amygdaloid neurons provoked by emotionally significant environmental stimuli in cats, with special reference to response durations. Can. J. Physiol. Pharm. 71: 374-378.

Maren, S., G. Aharonoz, and M.S. Fanselow. 1996. Retrograde abolition of conditional fear after excitotoxic lesions in the basolateral amygdala of rats: Absence of a temporal gradient. Behav. Neurosci. 110: 718-726.

Mathieson, W.B., P. Federico, W.L. Veale, and Q.J. Pittman. 1989. Single-unit activity in the bed nucleus of the stria terminalis during fever. Brain Res. 486: 49-55.

McDonald, A.J. and J.R. Augustine. 1993. Localization of GABA-like immunoreactivity in the monkey amygdala. Neuroscience 52: 281-294.

McGaugh, J.L., I.B. Introini-Collison, L.F. Cahill, C. Castellano, C. Dalmaz, M.B. Parent, and C.L. Williams. 1993. Neuromodulatory systems and memory storage: Role of the amygdala. Behav. Brain Res. 58: 81-90.

McGaugh, J.L., L. Cahill, and B. Roozendaal. 1996. Involvement of the amygdala in memory storage: Interaction with other brain systems. Proc. Natl. Acad. Sci.

93: 13508-13514.

Morgan, J.I. and T. Curran. 1991. Stimulus-transcription coupling in the nervous system: Involvement of the inducible proto-oncogenes fos and jun. Annu. Rev. Neurosci. 14: $421-451$.

Muller, R.U., J.L. Kubie, and J.B.J. Ranck. 1987. Spatial firing patterns of hippocampal complex-spike cells in a fixed environment. J. Neurosci. 7: 1935-1950.

Muramoto, K., T. Ono, H. Nishijo, and M. Fukuda. 1993. Rat amygdaloid neuron responses during auditory discrimination. Neuroscience 52: 621-636.

Ono, T., H. Nishijo, and T. Uwano. 1995. Amygdala role in conditioned associative learning. Prog. Neurobiol. 46: $401-422$.

Panula, P., A.V. Revuelta, D.L. Cheney, J.Y. Wu, and E. Costa. 1984. An immunohistochemical study on the location of GABAergic neurons in rat septum. J. Comp. Neurol. 222: $69-80$.

Parent, M.B. and J.L. McGaugh. 1994. Posttraining infusion of lidocaine into the amygdala basolateral complex impairs retention of inhibitory avoidance training. Brain Res. 661: 97-103.

Parent, M.B., M. West, and J.L. McGaugh. 1994. Memory of rats with amygdala lesions induced 30 days after footshock-motivated escape training reflects degree of original training. Behav. Neurosci. 108: 1080-1087.

Parent, M.B., G.L. Quirarte, L. Cahill, and J.L. McGaugh. 1995. Spared retention of inhibitory avoidance learning after posttraining amygdala lesions. Behav. Neurosci. 109: 803-807.

Paxinos, G. and C. Watson. 1986. The rat brain in stereotaxic coordinates. Academic Press, San Diego, CA.

Pfaff, D. and M. Keiner. 1973. Atlas of estradiol-concentrating cells in the central nervous system of the female rat. J. Comp. Neurol. 151: 121-158.

Pitkanen, A. and D.G. Amaral. 1994. The distribution of GABAergic cells, fibers, and terminals in the monkey amygdaloid complex: An immunohistochemical and in situ hybridization study. J. Neurosci. 14: 2200-2224.

Rajendren, G. and R.L. Moss. 1993. The role of the medial nucleus of the amygdala in the mating-induced enhancement of lordosis in female rats: The interaction with luteinizing hormone-releasing hormone neuronal system. Brain Res. 617: 81-86.

Risold, P.Y. and L.W. Swanson. 1996. Structural evidence for functional domains in the rat hippocampus. Science 272: 1484-1486.

Risold, P.Y., N.S. Canteras, and L.W. Swanson. 1994. Organization of projections from the anterior hypothalamic nucleus: A Phaseolus vulgaris-leucoagglutinin study in the rat. J. Comp. Neurol. 348: 1-40.

Rizvi, T.A., M. Ennis, and M.T. Shipley. 1992. Reciprocal connections between the medial preoptic area and the midbrain periaqueductal gray in rat: A WGA-HRP and PHA-L study. J. Comp. Neurol. 315: 1-15.

Rizvi, T.A., A.Z. Murphy, M. Ennis, M.M. Behbehani, and M.T. Shipley. 1996. Medial preoptic area afferents to periaqueductal gray medullo-output neurons: A combined Fos and tract tracing study. J. Neurosci. 16: 333-344.

Salinas, J.A., M.G. Packard, and J.L. McGaugh. 1993. Amygdala modulates memory for changes in reward magnitude: Reversible post-training inactivation with lidocaine attenuates the response to a reduction in reward. Behav. Brain Res. 59: 153-159.

Salinas, J.A., M.B. Parent, and J.L. McGaugh. 1996. Ibotenic acid lesions of the amygdala basolateral complex or central nucleus differentially effect the response to reductions in reward. Brain Res. 742: 283-293.

Sanders, S.K. and A. Shekhar. 1995. Anxiolytic effects of chlordiazepoxide blocked by injection of GABAA and benzodiazepine receptor antagonists in the region of the anterior basolateral amygdala of rats. Biol. Psychiatry 37: $473-476$.

Sandner, G., P. Oberling, M.C. Silveira, G. Di Scala, B. 
Rocha, A. Bagri, and R. Depoortere. 1993. What brain structures are active during emotions? Effects of brain stimulation elicited aversion on c-fos immunoreactivity and behavior. Behav. Brain Res. 58: 9-18.

Savander, V., C.G. Go, J.E. LeDoux, and A. Pitkanen. 1995. Intrinsic connections of the rat amygdaloid complex: Projections originating in the basal nucleus. J. Comp. Neurol. 361: 345-368.

Scalia, F. and S.S. Winans. 1975. The differential projections of the olfactory bulb and accessory olfactory bulb in mammals. J. Comp. Neurol. 161: 31-55.

Schulkin, J., J. Marini, and A.N. Epstein. 1989. A role for the medial region of the amygdala in mineralocorticoid-induced salt hunger. Behav. Neurosci. 103: 179-185.

Segovia, S. and A. Guillamon. 1993. Sexual dimorphism in the vomeronasal pathway and sex differences in reproductive behaviors. Brain Res. Rev. 18: 51-74.

Sharp, F.R., S.M. Sagar, K. Hicks, D. Lowenstein, and K. Hisanaga. 1991. c-fos mRNA, Fos, and Fos-related antigen induction by hypertonic saline and stress. J. Neurosci. 11: 2321-2331.

Shin, C., J.O. McNamara, J.I. Morgan, T. Curran, and D.R. Cohen. 1990. Induction of c-fos mRNA expression by afterdischarge in the hippocampus of naive and kindled rats. J. Neurochem. 55: 1050-1055.

Shindou, T., S. Watanabe, K. Yamamoto, and H. Nakanishi. 1993. NMDA receptor-dependent formation of long-term potentiation in the rat medial amygdala neuron in an in vitro slice preparation. Brain Res. Bull. 31: 667-672.

Simerly, R.B. and L.W. Swanson. 1986. The organization of neural inputs to the medial preoptic nucleus of the rat. $J$. Comp. Neurol. 246: 312-342.

1988. Projections of the medial preoptic nucleus: A Phaseolus vulgaris leucoagglutinin anterograde tract-tracing study in the rat. J. Comp. Neurol. 270: 209-242.

Simerly, R.B., C. Chang, M. Muramatsu, and L.W. Swanson. 1990. Distribution of androgen and estrogen receptor mRNA-containing cells in the rat brain: An in situ hybridization study. J. Comp. Neurol. 294: 76-95.

Slotnick, B. 1985. Olfactory discrimination in rats with anterior amygdala lesions. Behav. Neurosci. 99: 956-963.

Slotnick, B. and N. Kaneko. 1981. Role of mediodorsal thalamic nucleus in olfactory discrimination learning in rats. Science 214: 91-92.

Staiger, J.F. and F. Nurnberger. 1991. The efferent connections of the lateral septal nucleus in the guinea pig: Intrinsic connectivity of the septum and projections to other telencephalic areas. Cell Tissue Res. 264: 415-426.

Staubli, U., D. Fraser, M. Kessler, and G. Lynch. 1986.
Studies on retrograde and anterograde amnesia of olfactory memory after denervation of the hippocampus by entorhinal cortex lesions. Behav. Neural. Biol. 46: 432-444.

Staubli, U., O. Thibault, M. DiLorenzo, and G. Lynch. 1989. Antagonism of NMDA receptors impairs aquisition but not retention of olfactory memory. Behav. Neurosci. 103: 54-60.

Swanson, L.W. 1992. Brain maps: Computer graphics files. Professional version 1.0. Elsevier Science BV, Amsterdam, The Netherlands.

Swanson, L.W. and W.M. Cowan. 1977. An autoradiographic study of the organization of the efferent connections of the hippocampal formation in the rat. J. Comp. Neurol. 172: 49-84.

Van Groen, T. and J.M. Wyss. 1990. Extrinsic projections from area CA1 of the rat hippocampus: Olfactory, cortical, subcortical, and bilateral hippocampal formation projections. J. Comp. Neurol. 302: 515-528.

Vochteloo, J.D. and J.M. Koolhaas. 1987. Medial amygdala lesions in male rats reduce aggressive behavior: Interference with experience. Physiol. Behav. 41: 99-102.

Wiener, S.I., C.A. Paul, and H. Eichenbaum. 1989. Spatial and behavioral correlates of hippocampal neuronal activity. J. Neurosci. 9: 2737-2763.

Wright, C.I. and H.J. Groenewegen. 1995. Patterns of convergence and segregation in the medial nucleus accumbens of the rat: Relationships of prefrontal cortical, midline thalamic, and basal amygdaloid afferents. J. Comp. Neurol. 361: 383-403.

Wright, C.I., A.V. Beijer, and H.J. Groenewegen. 1996. Basal amygdaloid complex afferents to the rat nucleus accumbens are compartmentally organized. J. Neurosci. 16: 1877-1893.

Received June 2, 1997; accepted in revised form August 15, 1997.

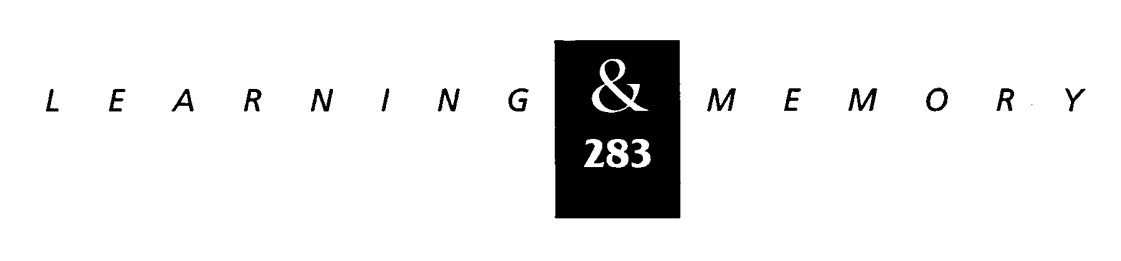




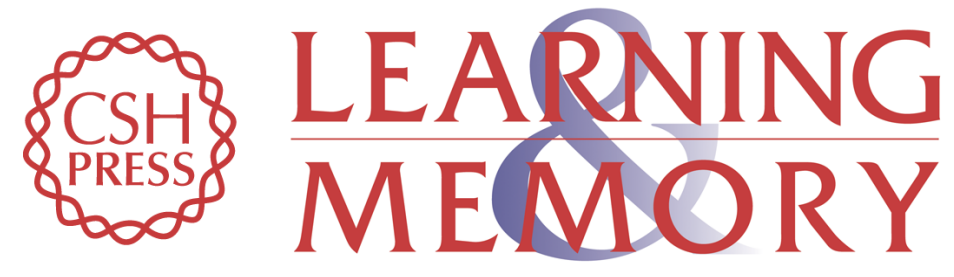

\section{Differential patterns of c-fos mRNA expression in amygdala during successive stages of odor discrimination learning.}

U S Hess, C M Gall, R Granger, et al.

Learn. Mem. 1997, 4:

Access the most recent version at doi:10.1101//m.4.3.262

References This article cites 48 articles, 10 of which can be accessed free at: http://learnmem.cshlp.org/content/4/3/262.full.html\#ref-list-1

License

Email Alerting Receive free email alerts when new articles cite this article - sign up in the box at the Service top right corner of the article or click here. 